\title{
Internal Solitons in the Northeastern South China Sea Part I: Sources and Deep Water Propagation
}

\author{
Steven R. Ramp, Tswen Yung Tang, Timothy F. Duda, James F. Lynch, Senior Member, IEEE, Antony K. Liu, \\ Ching-Sang Chiu, Frederick L. Bahr, Hyoung-Rok Kim, and Ying-Jang Yang
}

\begin{abstract}
A moored array of current, temperature, conductivity, and pressure sensors was deployed across the Chinese continental shelf and slope in support of the Asian Seas International Acoustics Experiment. The goal of the observations was to quantify the water column variability in order to understand the along- and across-shore low-frequency acoustic propagation in shallow water. The moorings were deployed from April 21-May 19,2001 and sampled at 1-5 min intervals to capture the full range of temporal variability without aliasing the internal wave field. The dominant oceanographic signal by far was in fact the highly nonlinear internal waves (or solitons) which were generated near the Batan Islands in the Luzon Strait and propagated $485 \mathrm{~km}$ across deep water to the observation region. Dubbed trans-basin waves, to distinguish them from other, smaller nonlinear waves generated locally near the shelf break, these waves had amplitudes ranging from 29 to greater than $140 \mathrm{~m}$ and were among the largest such waves ever observed in the world's oceans. The waves arrived at the most offshore mooring in two clusters lasting 7-8 days each separated by five days when no waves were observed. Within each cluster, two types of waves arrived which have been named type-a and type-b. The type-a waves had greater amplitude than the type-b waves and arrived with remarkable regularity at the same time each day, $24 \mathrm{~h}$ apart. The type-b waves were weaker than the type-a waves, arrived an hour later each day, and generally consisted of a single soliton growing out of the center of the wave packet. Comparison with modeled barotropic tides from the generation region revealed that: 1) The two clusters were generated around the time of the spring tides in the Luzon strait; and 2) The type-a waves were generated on the strong side of the diurnal inequality while the type-b waves were generated on the weaker beat. The position of the Kuroshio intrusion into the Luzon Strait may modulate the strength of the waves being produced. As the waves shoaled, the huge lead solitons first split into two solitons then merged together into a broad region of thermocline depression at depths less than $120 \mathrm{~m}$. Elevation waves sprang up behind them as they continued to propagate onshore. The elevation waves also grew out of regions where the locally-generated internal tide forced the main thermocline down near the bottom. The "critical
\end{abstract}

Manuscript received June 6, 2003; revised April 2, 2004. The planning, execution, and analysis of this work was supported by the U.S. Office of Naval Research Ocean Acoustics and Physical Oceanography Programs. Significant funding contributions were also made by the National Science Council of Taiwan.

S. R. Ramp, C.-S. Chiu, and F. L. Bahr are with the Department of Oceanography, Naval Postgraduate School, Monterey, CA 93943 USA.

T. Y. Tang is with the Institute of Oceanography, National Taiwan University, Taipei, ROC.

H.-R. Kim was with the Department of Oceanography, Naval Postgraduate School, Monterey, CA 93943 USA. He is now at Seoul National University, Seoul, South Korea.

T. F. Duda and J. F. Lynch are with the Woods Hole Oceanographic Institution, Woods Hole, MA 02543 USA.

A. K. Liu is with the NASA Goddard Space Flight Center, Greenbelt, MD 20771 USA.

Y.-J. Yang is with the Chinese Naval Academy, Kaohsiung, Taiwan, ROC.

Digital Object Identifier 10.1109/JOE.2004.840839 point" $\alpha$ where the upper and lower layers were equal was a good indicator of when the depression or elevation waves would form, however this was not a static point, but rather varied in both space and time according to the presence or absence of the internal tides and the incoming trans-basin waves themselves.

Index Terms-Baroclinic tides, nonlinear internal waves, ocean currents.

\section{INTRODUCTION}

\section{A. The ASIAEX Program}

$\mathbf{T}$ HE Asian Seas International Acoustics Experiment (ASIAEX) was a major field effort in coupled physical oceanography, geophysics, and environmental acoustics which took place during the consecutive springs of 2000 and 2001 in the South and East China Seas. The program was divided into two major components, a volume interaction experiment in the South China Sea (SCS), with Taiwan and Singapore as the primary collaborators, and a boundary interaction experiment in the East China Sea (ECS), with the People's Republic of China (PRC) and Korea as the primary international partners. The overarching goal of the SCS volume interaction experiment was to understand acoustic propagation through shallow water when strong oceanic variability in the form of fronts, eddies, boundary layers, and internal waves, is present. The goal of the boundary interaction experiment was to develop models that can predict the mean reverberation level and fluctuations using measured environmental parameters. Both experiments were multiship operations and required close cooperation between acousticians, physical oceanographers, and geophysicists. All the partnering nations contributed human and financial resources to the program, which allowed a larger and more comprehensive experiment than would otherwise have been possible. This paper presents results from the SCS volume interaction experiment. Results from the ECS program are presented elsewhere in this special issue.

The science plan for the 2001 SCS experiment called for simultaneous observations of the water column properties (temperature, salinity, and velocity) and acoustic propagation characteristics at very high resolution in space and time. This was accomplished by a combination of moored and shipboard observations near the continental shelf break between the southern tip of Taiwan and Dongsha Island (also called Pratis Reef) bounded by 21 to $22.5^{\circ} \mathrm{N}, 117$ to $119^{\circ} \mathrm{E}$ (Fig. 1). The moored array consisted of seven densely instrumented oceanographic moorings (S8-S2) deployed in an across-shelf line spanning 800 to $72 \mathrm{~m}$ 


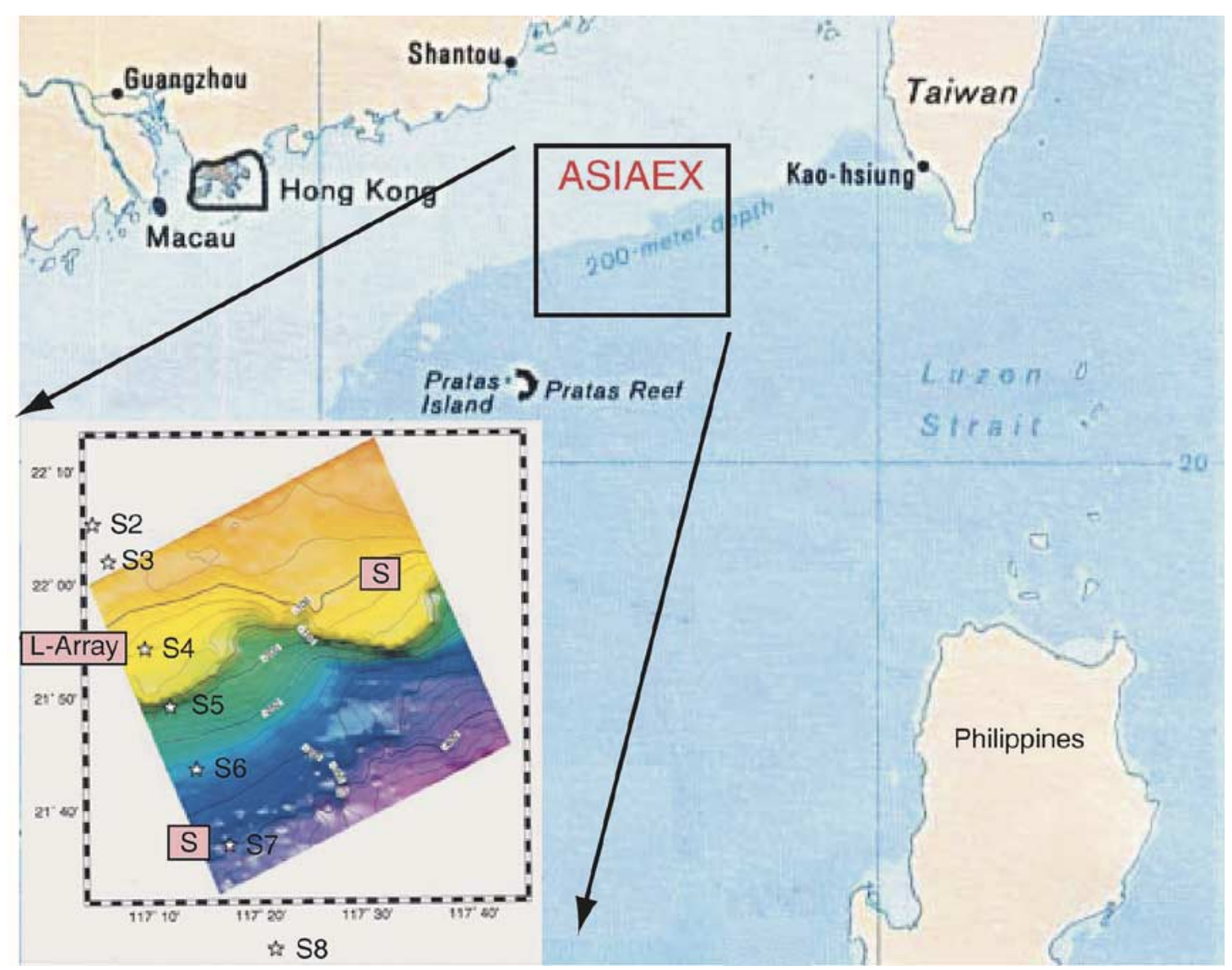

Fig. 1. Locator map showing the positions of the ASIAEX moorings. The current meter moorings are indicated by stars labeled S2-S8. The shaded red boxes indicate acoustic assets, with an "S" indicating sources and "L-Array" the horizontal and vertical receiving arrays.

(Fig. 1). These moorings were designed to be along the primary acoustic transmission paths. Two sound sources operating at 224 and $400 \mathrm{~Hz}$ were deployed on the $350 \mathrm{~m}$ isobath and sources operating at 300,400 , and $500 \mathrm{~Hz}$ were deployed on the $120 \mathrm{~m}$ isobath (Fig. 1). The acoustic signals were all received at an L-shaped hydrophone array with both horizontal and vertical apertures, also moored on the $120 \mathrm{~m}$ isobath. While the acoustics results are not explicitly discussed in this paper, the mooring locations are included to foster comparisons presented elsewhere [1], [2].

While the moorings were in the water, shipboard surveys continuously mapped the area to ascertain the three-dimensional spatial scales and representativeness of the moorings. On the OCEAN RESEARCHER 1 (OR1), two surveys were conducted using the SeaSoar towed undulating vehicle: The small-scale SeaSoar survey mapped the three-dimensional water mass properties in the insonified region and a larger-scale survey described the surrounding mesoscale variability [3]. A second vessel, the OCEAN RESEARCHER 3 (OR3) steamed dedicated cruise tracks in the vicinity of the acoustic transmission paths [4]. Both vessels collected temperature, conductivity, and hull-mounted ADCP velocity data as a function of pressure (depth). The SeaSoar aboard OR1 additionally sampled fluorescence, bioluminescence, and light transmission while the OR3 sampled high frequency acoustic backscatter at 200 and
$350 \mathrm{kHz}$ for flow visualization of internal waves and evaluation of turbulence.

This manuscript focuses on results from the SCS program during spring 2001, with occasional reach-back to spring 2000 for critical supporting information. The primary analysis concerns internal wave variability as derived from the moored observations of current, temperature, and salinity. A rich field of strongly nonlinear internal solitary waves (solitons) was observed from several different platforms during the course of the experiment. This paper identifies the basic characteristics of the waves, their sources, and their propagation characteristics. The tidal, mesoscale, and interannual variability are mentioned only peripherally as they pertain to understanding the internal wave dynamics. These lower-frequency motions are the primary focus of several other manuscripts in this volume.

\section{B. Location and Basin Geometry}

The South China Sea is one of a chain of marginal seas along the western Pacific Ocean. It fits into the chain between the Indonesian Seas to the south and the East China Sea, Japan (East) Sea, and the Okhotsk Sea to the north. The sea can be generally characterized as a deep $(>4000 \mathrm{~m})$ basin bordered by a broad $(220 \mathrm{~km})$, shallow $(<100 \mathrm{~m})$ continental shelf to the north and west and a tropical island chain with almost no continental shelf to the south. The SCS is connected to the surrounding seas and 
the open north Pacific (the Philippine Sea) by a number of straits with varying width and depth. Clearly the most important one is the Luzon strait located between Taiwan and the Island of Luzon in the Philippines, with a sill depth of about $1900 \mathrm{~m}$. Most of the transport into the SCS comes from this strait, as does all of the ventilation in the SCS deep basin. There are several small island groups within the Luzon strait, some of which have very small, shallow passages between islands. These islands do not appreciably inhibit the mass transport through the strait, but may be important to the local dynamics as the generation point for the internal solitons observed propagating across the northeastern corner of the sea [5]-[7]. In the northeast sector of the SCS, between the Luzon Strait and ASIAEX region, the central basin is more than $4000 \mathrm{~m}$ deep with no islands, banks, or other shallow spots in between. The Taiwan Strait lies between the Chinese mainland and the island of Taiwan. The mass transport through this shallow $(60 \mathrm{~m})$, narrow $(140 \mathrm{~km})$ strait is limited [8]. Its importance to ASIAEX lies in its amplification of the semidiurnal tide and introduction of fresh water to the region. This forcing and the resulting fronts and stratification do impact the acoustic propagation. The remaining connections between the SCS and its neighboring seas and basins are all too narrow or shallow to allow appreciable volume transport. They are quite distant from the ASIAEX region and have no discernable impact on the observational results reported here.

\section{Forcing by Wind}

The SCS wind forcing is dominated by a summer monsoon which blows from the southwest to northeast, and a winter monsoon of opposite sign. In contrast to the well known Indian Ocean monsoon, the northeast (winter) monsoon in the SCS is the stronger one and dominates the annual statistics. The summer SW monsoon develops in June, reaches a maximum (order $0.15 \mathrm{~Pa}$ ) in August, and begins to weaken in September [9]. In October, the transition to NE winds begins in the northern part of the basin and spreads southward, reaching maximum force (order 0.3 Pa) in December through March. April and May are transition months with the calmest seas, which influenced the timing of the ASIAEX experiments. A wild-card in the ASIAEX planning was the formation of monsoon depressions which can sometimes develop into tropical cyclones. On average, about four monsoon depressions form per year between May and September, most frequently during August to September. May 2001 was unusual in that a weak tropical cyclone did occur. This storm was initially headed directly toward the ASIAEX region and several research vessels at sea, but the eye fortunately veered NE into the Luzon Strait on May 12 and did not pass through the ASIAEX box. Anomalous surface wind stress which resulted from the storm did impact the moored data, particularly the moorings in less than $80 \mathrm{~m}$ of water.

An important consequence of the monsoon variability is the presence or absence of the Kuroshio Current in the northeastern South China Sea. The Kuroshio stems from the North Equatorial Current and flows northwest along the Philippines, across the Luzon Strait on the Pacific side, and continues along the south coast of Taiwan. Sometimes, however, the current enters the SCS via the southern portion of the Luzon Strait, loops through the northeast corner of the sea, and then exits again via the northern Luzon Strait. The character of this "Kuroshio Intrusion" (KI) is intermittent and highly seasonal. Most of the inflow occurs in fall and winter when it is supported by the NE monsoon, which lowers the sea level/pressure head inside the SCS and encourages the intrusion to enter. Numerical models [10] produce an intrusion in the winter but not in the summer. Observations are sparse but also show greater incursions of Kuroshio water during winter than summer [11]. The nature of the KI within the SCS is also variable. The current may retroflect entirely and leave the sea via the northern Luzon Strait. It may also bifurcate at the shelf break, with some water leaving and some turning southwest along the continental slope. This current is traceable along the entire shelf as a salinity maximum near $150 \mathrm{~m}$ depth over the slope. Finally, the KI loop current will occasionally detach and form a large warm core ring which propagates WSW into the sea. The importance of these processes for this paper is that the flow across the sills in the Luzon Strait depends strongly on the position of the Kuroshio is doing. The total flow, tidal plus mesoscale currents, determines how and when the internal solitons will be generated. The mean currents in the northeast SCS will also impact the apparent propagation speed of the internal waves as they move WNW from the generating sills to the observation point on the Chinese continental shelf.

\section{Tides}

The barotropic tidal waves for both the M2 and K1 tides enter the SCS through the Luzon Strait and travel rapidly southwestward down the basin [12]. Upon striking the Sunda Shelf, topographic effects become important and refract the tidal waves both left and right into the Gulf of Thailand and the Java Sea. The strongest semidiurnal tides in the SCS are observed in the NE corner near the Taiwan Strait [13]. The amplitude of the M2 tide does not increase southward in the open water $(20 \mathrm{~cm}$ everywhere) but $\mathrm{K} 1$ does ( 20 to $40 \mathrm{~cm}$ ). This is very unusual for such low latitudes and is because the whole basin may have a natural period quite close to diurnal [14]. The Gulfs of Tonkin and Thailand are very nearly quarter-wave resonators for the K1 tide which leads to very strong diurnal amplification in these regions. The tides throughout the basin are thus mixed, with some regions (the far north and off Borneo and Vietnam) being dominated by the M2 tide and other regions (open water and the two gulfs) being dominated by the $\mathrm{K} 1$.

\section{E. Internal Waves}

As observational techniques have improved and scientists have moved toward ever faster sampling speeds, internal waves have emerged as ubiquitous on the world's continental shelves, in marginal seas, and near straits and restrictions where high-speed flow occurs. The South China Sea is no exception: Synthetic Aperture Radar (SAR) imagery [7], [15] and moored Doppler profilers and thermistor chains [5] and [6] have revealed strong nonlinear internal waves or solitons present in the northeastern SCS between Luzon Strait and the Chinese continental shelf, propagating slightly north of due west. The SCS pilot study moorings [16] clearly observed these motions, 
and they influenced the design of the moorings for the main field program.

The study of internal waves has been generally divided among the generation, propagation, and dissipation problems. As will be seen, the generation region for the waves (the Luzon Strait) can be deduced from the ASIAEX observations, but save for the satellite remote sensing, there were no observations conducted there. There are many instances in the literature associating the generation of strong nonlinear internal waves with sills, straits, and abrupt topography, for instance in the Mediterranean [17], [18] fjord-like structures [18], [19] and at continental shelf breaks [21]-[24]. Generation is most often attributed in some way to tidal flow across abrupt topography [19], [20], [25]-[27] and the ASIAEX waves would appear to fit this description. Lacking in situ information at the generation site to describe the dynamics, this manuscript will focus mainly on describing the wave propagation through deep water and their transformation as they enter the shallower water over the continental shelf and slope. Wave generation will be discussed to the extent possible using a global tidal model for the generation region.

The propagation of small or moderate amplitude solitary waves has been well described by two-layer Korteweg-de Vries (KdV) theory [28]-[31]. The waves evolve into the classic hyperbolic secant-squared shape as a balance between nonlinear effects and dispersion. Continuous stratification has been included in the problem by decomposing the particle velocities $(\mathrm{u}, \mathrm{v}$, and $\mathrm{w})$ and wave displacements $(\eta)$ into a linear combination of vertical modes [23], [26], [32]. Recently, other lesser-known solutions to the KdV equation have been pursued (cnoidal and dnoidal) which produce many of the observed characteristics of solitary wave packets much better than the $\operatorname{sech}^{2}$ solution [23], [33]. The dnoidal solution, for instance, reproduces the rank-ordered nature of the wave packets and the trailing thermocline depression they leave behind.

When solitary waves enter shoal water, the upper and lower layer depths become nearly equal, the first-order nonlinearity term in the $\mathrm{KdV}$ equation goes to zero, and second-order nonlinearity must be invoked to balance wave dispersion [32], [34]. The simple KdV theory produces unrealistic results in this case and the second-order or extended KdV (EKdV) theory is needed. The $\mathrm{KdV}$ solution for instance produces wave amplitudes which continue to grow as the water shoals, whereas the EKdV result provides amplitudes which first grow but then diminish in accordance with the observations. Two-dimensional horizontal solutions $(\mathrm{x}, \mathrm{y}, \mathrm{z})$ are required to understand wave refraction by topography and radial spreading [35], [36]. This paper will consider observational results from a single linear mooring line approximately normal to the continental shelf break and will not attempt to address the two-dimensional results. Ultimately, the wave energy must be dissipated on the Chinese continental shelf via friction, refraction, wave breaking, and radial spreading [27], [35], [37]. These processes are better described by the ASIAEX Low-Cost (LOCO) Moorings located further onshore and are the focus of other ASIAEX papers [2], [4].

Of all the major sea-going internal wave studies to date, the one most closely resembling the ASIAEX configuration was the Sulu Sea study conducted during May 1980 from the R/V OCEANOGRAPHER [26], [35]. The season, stratification, longitude, and basin configuration together allowed the waves to travel great distances over deep water before shoaling on the other side, and were all quite similar to the situation presented in the northeastern South China Sea. At the time of their study, the wave amplitudes, associated wave velocities, distance traveled, and lifetimes were among the largest ever observed. Good agreement was found between the observed wave characteristics and modal solutions to a finite-depth version of the $\mathrm{KdV}$ equation [38], [39]. The South China Sea waves were actually larger and propagated farther than the Sulu Sea waves. The waves in both regions were parametrically similar in some ways but different in others, and extensive comparisons with the Sula Sea results will be made as this paper goes along.

\section{DATA AND METHODS}

The primary instruments deployed on the physical oceanography $(\mathrm{PO})$ moorings were temperature $(\mathrm{T})$ pods; temperature and pressure (TP) sensors; temperature, conductivity, and pressure (TCP) sensors; and several generations of acoustic Doppler current profilers (ADCP's) operating at different frequencies according to the range desired (Fig. 2, Table I). One mooring on the $350 \mathrm{~m}$ isobath had three additional Aanderaa RCM8 current meters below the ADCP to sample the deeper currents over the continental slope. The nomenclature S1-S8 has been adopted for the moorings, with S2-S8 forming the across-shore line and S1 located off to the northeast along the $80 \mathrm{~m}$ isobath. Fishing activity was intense in the area but the mooring survival rate was excellent under the circumstances. Mooring S1 was lost, the ADCP on mooring S8 did not function, and mooring S3 was sliced in half and dragged by fishermen. The upper half of the mooring was recovered after visual sighting by the OR 1 , and the bottom half was recovered by dragging during the final cruise on the OR1. Thus, a mostly complete data set was recovered along the main line spanning 72 to $350 \mathrm{~m}$ depth (S2-S7).

Anticipating an active internal wave field from the spring 2000 results, all instruments were set to sample as fast as possible within the constraints of instrument power and internal memory. The T, TP, and TCP sensors collected discrete samples at one-minute intervals (some at two-minutes) and the ADCP's pinged continuously at one-second intervals, recording ensemble averages every one or two minutes. For those sampling at one minute, additional memory and external battery packs were installed to facilitate this sampling rate over one month's time. The bin length was $10 \mathrm{~m}$ for the $150 \mathrm{kHz}$ broadband $\mathrm{ADCP}$ at $\mathrm{S} 6 ; 8 \mathrm{~m}$ for the $150 \mathrm{kHz}$ narrowband at S5; and $4 \mathrm{~m}$ for the $300 \mathrm{kHz}$ broadbands at the other moorings (Table I). The Aanderaa current meters recorded 2-min vector averages and seemed to work well despite the difficult conditions resulting from the high currents associated with the internal waves. The near-bottom SBE26 pressure gauges sampled at 5-min intervals which was more than adequate to sample the barotropic tide. The T, TP and TCP instruments were calibrated both before and after the experiment by the manufacturer.

To facilitate this analysis, the time series were digitally filtered into three bands; the internal wave (IW) band, the tidal (T) 


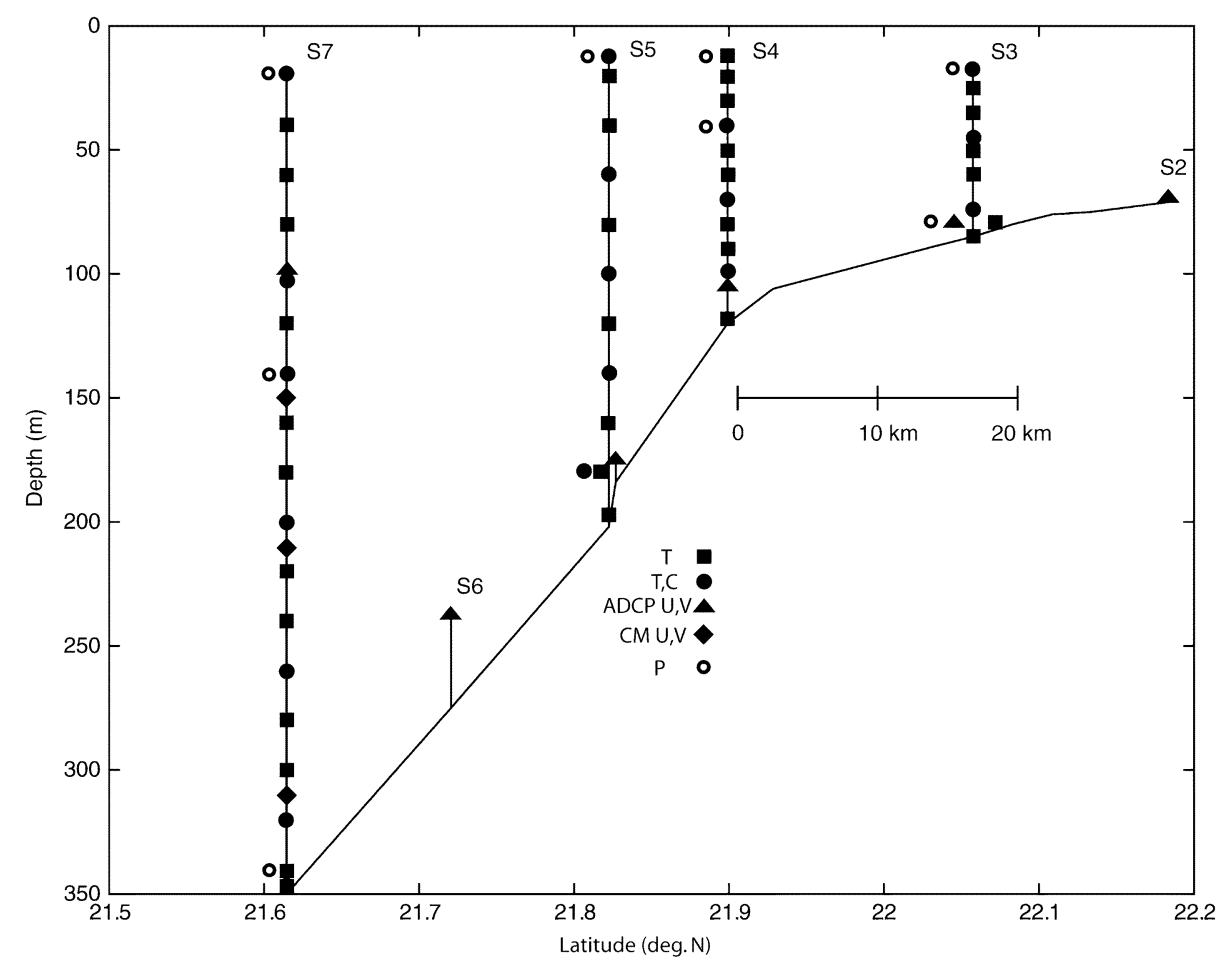

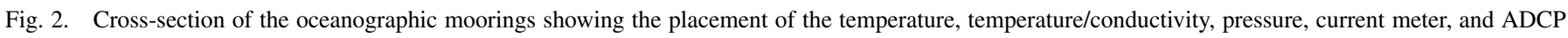
instruments in the water column.

band, and the low-frequency (LF) or mesoscale band. The data were first run through a well-known low-pass filter originating at Oregon State University [40] with a half-power point at forty-six hours. This filter does an excellent job of separating the tidal, inertial, and higher-frequency motions from the mesoscale variability. The low-passed data were then subtracted from the original time series to remove the low frequency content, including the mean value. This intermediate time series was subsequently filtered again in frequency space to separate the internal waves from the tidal and inertial motions. The Fourier coefficients for periods shorter than $5 \mathrm{~h}$ were removed and the series were inverse-transformed to produce the band-passed times series, which were in turn subtracted from the intermediate series to produce the high-passed series. This technique was used in lieu of time-space filtering due to the enormous internal wave spikes which were not adequately attenuated using the usual convolution methods. The resulting time series thus spanned less than 46 hours (LF), 46-5 h (T), and $5 \mathrm{~h}$ and above (IW). Little attention is paid in this paper to inertial motions, but it is worth noting here that the inertial period at $22^{\circ} \mathrm{N}$ is 32 hours so that both the semidiurnal and diurnal internal tides were superinertial, i.e., within the freely propagating internal wave band.

\section{RESULTS}

\section{A. Oceanographic Context}

The emphasis in this manuscript is on describing and understanding the internal waves, however some knowledge of the background flows and their relative strengths is useful to understand certain features of the wave observations. At depths of $150 \mathrm{~m}$ and greater over the continental slope, the mean flow closely followed the topography toward the southwest at around
$10 \mathrm{~cm} \mathrm{~s}^{-1}$ with a low frequency standard deviation of about $6 \mathrm{~cm} \mathrm{~s}^{-1}$. At shallower depths, there was an increasingly onshore component to the month-long mean. These currents had a subsurface maximum of about $15 \mathrm{~cm} \mathrm{~s}^{-1}$ near $100 \mathrm{~m}$ depth at mooring S5. There was no hint of the northeastward-flowing South China Sea Warm Current (SCSWC), nor were there any major Kuroshio intrusions [3]. On the continental shelf inshore of mooring S4, the low-frequency standard deviations $(15 \mathrm{~cm}$ $\left.\mathrm{s}^{-1}\right)$ exceeded the mean flows $\left(<3 \mathrm{~cm} \mathrm{~s}^{-1}\right)$ indicating that the mean flows on the shelf were not well resolved by these short records. This time period resembled the inter-monsoon, rather than the late-winter monsoon like in April 2000 [3]. The primary utility of the mean currents for this paper lies in the advection and background shear they present to the internal wave field. The vertical shear perhaps accounts for some of the variability in the observed internal wave propagation speeds discussed subsequently.

The mean currents in the tidal band were enormously complex indicating that there was significant baroclinic energy at these frequencies. This was particularly true at the slope moorings (S5-S7) where the tidal ellipses displayed a variety of sizes and orientations as a function of depth. The tides on the shelf were more organized. Statistically speaking, the current magnitudes in the tidal band ranged from 40 to $60 \mathrm{~cm} \mathrm{~s}^{-1}$ across the entire array with standard deviations from 15 to $22 \mathrm{~cm} \mathrm{~s}^{-1}$, much stronger than the mean currents yet much weaker than the internal waves. The tides are the subject of two related manuscripts in this volume on the barotropic [41] and baroclinic [2] tides. Noteworthy here is the relationship between the internal tide (period 12-24 $\mathrm{h}$ ) and the observed large amplitude internal waves (period minutes to $2 \mathrm{~h}$ ). Isolated packets of large amplitude, nonlinear internal waves have been referred to as solitons. 
TABLE I

MOORING LOCATIONS AND INSTRUMENT DEPTHS FOR ALl THE ENVIRONMENTAL MOORINGS DEPLOYED DURING ASIAEX, APRIL-MAY 2001. FOR EACH ADCP, THE FREQUENCY OF OPERATION, BROADBAND (BB) OR NARROWBAND (NB), AND DEPTH CELL LENGTH (m) IS INDiCATED. The ADCP at Site 5 Was on Its OWn Mooring (S5a). The Rest of the TABle Is SElf-Explanatory

\begin{tabular}{|c|c|c|c|c|c|c|c|c|}
\hline Mooring & Latitude & Longitude & $\begin{array}{l}\text { Bottom } \\
\text { Depth } \\
\text { (m) }\end{array}$ & $\begin{array}{l}\text { Instr. } \\
\text { Depth } \\
(\mathrm{m})\end{array}$ & Start & Stop & $\begin{array}{l}\text { Record } \\
\text { Length } \\
\text { (days) }\end{array}$ & $\begin{array}{c}\text { sample } \\
\text { Interval } \\
\text { (min) }\end{array}$ \\
\hline S8 & 2053.00 & 11733.986 & 792 & & & & & \\
\hline \multicolumn{3}{|c|}{$\begin{array}{l}\text { ADCP BB } 150 \mathrm{kHz} / 10 \mathrm{~m} \\
\text { SeaCAT } \\
(\text { TCP) }\end{array}$} & & 242 & $4 / 23 / 2001$ & $5 / 21 / 2001$ & 27.8 & 2 \\
\hline S7 & 2136.871 & 11716.975 & 350 & & & & & \\
\hline \multicolumn{2}{|c|}{ MicroCAT (TCP) } & & & 20 & $4 / 21 / 2001$ & $5 / 18 / 2001$ & 27.9 & 1 \\
\hline \multicolumn{2}{|c|}{ Starmon-mini } & & & 40 & $4 / 21 / 2001$ & $5 / 18 / 2001$ & 27.9 & 1 \\
\hline \multicolumn{2}{|c|}{ Starmon-mini } & & & 60 & $4 / 21 / 2001$ & $5 / 18 / 2001$ & 27.9 & 1 \\
\hline \multicolumn{2}{|c|}{ Starmon-mini } & & & 80 & $4 / 21 / 2001$ & $5 / 18 / 2001$ & 27.9 & 1 \\
\hline \multicolumn{2}{|c|}{ SeaCat } & & & 100 & No Data & & & \\
\hline \multicolumn{2}{|c|}{ ADCP BB $300 \mathrm{kHz} / 4 \mathrm{~m}$} & & & 100 & $4 / 21 / 2001$ & $5 / 19 / 2001$ & 27.9 & 1 \\
\hline \multicolumn{2}{|c|}{ Starmon-mini } & & & 120 & $4 / 21 / 2001$ & $5 / 18 / 2001$ & 27.9 & 1 \\
\hline \multicolumn{2}{|c|}{ MicroCAT (TCP) } & & & 140 & $4 / 21 / 2001$ & $5 / 18 / 2001$ & 27.9 & 1 \\
\hline \multicolumn{2}{|c|}{ Aanderra RCM 8} & & & 150 & $4 / 21 / 2001$ & $5 / 18 / 2001$ & 27.9 & 2 \\
\hline \multicolumn{2}{|c|}{ Starmon-mini } & & & 160 & $4 / 21 / 2001$ & $5 / 18 / 2001$ & 27.9 & 1 \\
\hline \multicolumn{2}{|c|}{ Starmon-mini } & & & 180 & $4 / 21 / 2001$ & $5 / 18 / 2001$ & 27.9 & 1 \\
\hline \multicolumn{2}{|c|}{ MicroCAT (TC) } & & & 200 & $4 / 21 / 2001$ & $5 / 18 / 2001$ & 27.9 & 1 \\
\hline \multicolumn{2}{|c|}{ Aanderra RCM 8} & & & 210 & $4 / 21 / 2001$ & $5 / 18 / 2001$ & 27.9 & 2 \\
\hline \multicolumn{2}{|c|}{ Seamon-mini } & & & 220 & $4 / 22 / 2001$ & $5 / 18 / 2001$ & 26.5 & 2 \\
\hline \multicolumn{2}{|c|}{ Seamon-mini } & & & 240 & No Data & & & \\
\hline \multicolumn{2}{|c|}{ MicroCAT } & & & 260 & $4 / 21 / 2001$ & $5 / 18 / 2001$ & 27.9 & 1 \\
\hline \multicolumn{2}{|c|}{ Seamon-mini } & & & 280 & $4 / 22 / 2001$ & $5 / 18 / 2001$ & 26.5 & 2 \\
\hline \multicolumn{2}{|c|}{ Seamon-mini } & & & 300 & $4 / 22 / 2001$ & $5 / 18 / 2001$ & 26.5 & 2 \\
\hline \multicolumn{2}{|c|}{ Aanderra RCM 8} & & & 310 & $4 / 21 / 2001$ & $5 / 18 / 2001$ & 27.9 & 2 \\
\hline \multicolumn{2}{|c|}{ SeaCAT (TC) } & & & 320 & $4 / 21 / 2001$ & $5 / 18 / 2001$ & 27.9 & 1 \\
\hline \multicolumn{2}{|c|}{ Seaguage SBE26 (TP) } & & & 344 & $4 / 21 / 2001$ & $5 / 18 / 2001$ & 27.9 & 5 \\
\hline \multicolumn{2}{|c|}{ Seamon-mini } & & & 346 & $4 / 22 / 2001$ & $5 / 18 / 2001$ & 26.5 & 2 \\
\hline S6 & 2143.24 & 11714.60 & 275 & & & & & \\
\hline \multirow{2}{*}{\multicolumn{3}{|c|}{$\begin{array}{l}\text { ADCP BB } 150 \mathrm{kHz} / 10 \mathrm{~m} \\
\text { SeaCAT (TCP) }\end{array}$}} & & 238 & $4 / 21 / 2001$ & $5 / 19 / 2001$ & 28 & 2 \\
\hline & & & & 243 & $4 / 21 / 2001$ & $5 / 19 / 2001$ & 28 & 2 \\
\hline S5 & 2149.346 & 11712.328 & 202 & & & & & \\
\hline MicroCAT & TCP) & & & 14 & $4 / 21 / 2001$ & $5 / 18 / 2001$ & 27 & 1 \\
\hline Seamon-m & & & & 22 & Bad Data & & & \\
\hline Seamon-m & & & & 42 & $4 / 22 / 2001$ & $5 / 18 / 2001$ & 25.8 & 2 \\
\hline MicroCAT & TC) & & & 62 & $4 / 21 / 2001$ & $5 / 18 / 2001$ & 27 & 1 \\
\hline Seamon-m & & & & 82 & $4 / 22 / 2001$ & $5 / 12 / 2001$ & 20.29 & 2 \\
\hline MicroCAT & TC) & & & 102 & $4 / 21 / 2001$ & $5 / 18 / 2001$ & 27 & 1 \\
\hline Seamon-m & & & & 122 & Bad Data & & & \\
\hline MicroCAT & TC) & & & 142 & $4 / 21 / 2001$ & $5 / 18 / 2001$ & 27 & 1 \\
\hline Seamon-m & & & & 162 & $4 / 22 / 2001$ & $5 / 18 / 2001$ & 25.8 & 2 \\
\hline MicroCAT & TC) & & & 182 & $4 / 21 / 2001$ & $5 / 18 / 2001$ & 27.02 & 1 \\
\hline Seamon-m & & & & 199 & No Data & & & \\
\hline
\end{tabular}

The internal tide itself has been referred to as an undular bore when it is particularly strong. When the solitons ride on the leading edge of an undular bore, they are called solibores. In this manuscript, we shall henceforth refer to the waves as solitons (or packets of solitons), because in the ASIAEX region they were usually but not always associated with the undular bore at tidal frequencies. Perhaps they began life that way, but evolved into soliton packets as they traveled the great distance $(485 \mathrm{~km})$ between the source region and the point of observation. More observations are needed in the source and propagation regions to understand this point. We return to the relationship between the internal tide and the ASIAEX solitons later on in the paper.

Clearly, the most powerful motions contained in the data were observed in the internal wave band. The maximum currents of $\left(-163,120 \mathrm{~cm} \mathrm{~s}^{-1}\right)$ at $\mathrm{S} 7$ for the $(\mathrm{u}, \mathrm{v})$ components were far stronger than the currents in the tidal or low frequency bands. The total flow $\left(\sqrt{u^{2}+v^{2}}\right)$ in the upper layer due to the waves routinely exceeded $120 \mathrm{~cm} \mathrm{~s}^{-1}$ at this mooring. At moorings S6 and S5 the IW currents were about double the tidal and low-frequency flows. From S4 on in, the IW and tidal currents had about the same magnitude, both stronger than the means. The internal waves statistically had opposing currents in the upper and lower layers around a nodal point whose depth varied between moorings. The nodal point statistically fell near $140 \mathrm{~m}$ at $\mathrm{S} 7$ and $100 \mathrm{~m}$ at S6 and S5. Further inshore there was much temporal variation and the nodal point varied from wave to wave. Some case studies of the modal structure of individual waves is presented later. The statistics provide a snapshot summary of the internal wave variance which is impressive in its own right. 
TABLE I

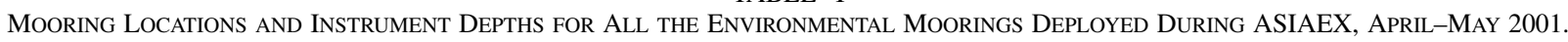
FOR EACH ADCP, THE FREQUENCY OF OPERATION, BROADBAND (BB) OR NARROWBAND (NB), AND DEPTH CELL LENGTH (m) Is INDiCATED.

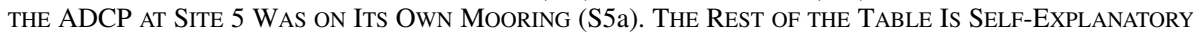

\begin{tabular}{|c|c|c|c|c|c|c|c|c|}
\hline Mooring & Latitude & Longitude & $\begin{array}{c}\text { Bottom } \\
\text { Depth } \\
\text { (m) }\end{array}$ & $\begin{array}{c}\text { Instr. } \\
\text { Depth } \\
(\mathrm{m})\end{array}$ & Start & Stop & $\begin{array}{l}\text { Record } \\
\text { Length } \\
\text { (days) }\end{array}$ & $\begin{array}{c}\text { sample } \\
\text { Interval } \\
\text { (min) }\end{array}$ \\
\hline S5a & 2149.616 & 11712.240 & 184 & & & & & \\
\hline \multirow{2}{*}{\multicolumn{4}{|c|}{$\begin{array}{l}\text { ADCP NB } 150 \mathrm{kHz} / 8 \mathrm{~m} \\
\text { Seamon-mini }\end{array}$}} & 177 & $4 / 21 / 2001$ & $5 / 18 / 2001$ & 27.1 & 2 \\
\hline & & & & 180 & $4 / 22 / 2001$ & $5 / 18 / 2001$ & 25.9 & 2 \\
\hline S4 & 2153.944 & 11710.619 & 120 & & & & & \\
\hline \multicolumn{4}{|c|}{ SBE $39(T P)$} & 11 & $4 / 21 / 2001$ & $5 / 19 / 2001$ & 27.8 & 0.5 \\
\hline \multicolumn{4}{|c|}{ Mini-Starmon } & 19 & $4 / 21 / 2001$ & $5 / 19 / 2001$ & 27.8 & 1 \\
\hline \multicolumn{4}{|c|}{ Mini-Starmon } & 29 & Bad Data & & & \\
\hline \multicolumn{4}{|c|}{ MicroCAT (TCP) } & 39 & $4 / 21 / 2001$ & $5 / 19 / 2001$ & 27.8 & 1 \\
\hline \multicolumn{4}{|c|}{ Seamon-mini } & 49 & No data & & & \\
\hline \multicolumn{4}{|c|}{ Seamon-mini } & 59 & $4 / 22 / 2001$ & $5 / 19 / 2001$ & 26.8 & 2 \\
\hline \multicolumn{4}{|c|}{ MicroCAT (TC) } & 70 & $4 / 21 / 2001$ & $5 / 19 / 2001$ & 27.8 & 1 \\
\hline \multicolumn{4}{|c|}{ Seamon-mini } & 80 & $4 / 22 / 2001$ & $5 / 19 / 2001$ & 26.8 & 2 \\
\hline \multicolumn{4}{|c|}{ Seamon-mini } & 90 & $4 / 22 / 2001$ & $5 / 19 / 2001$ & 26.8 & 2 \\
\hline \multicolumn{4}{|c|}{ MicroCAT (TC) } & 100 & $4 / 21 / 2001$ & $5 / 19 / 2001$ & 27.8 & 1 \\
\hline \multicolumn{4}{|c|}{ ADCB BB $300 \mathrm{kHz} / 4 \mathrm{~m}$} & 104 & $4 / 21 / 2001$ & $5 / 19 / 2001$ & 27.8 & 1 \\
\hline \multicolumn{4}{|c|}{ Seamon-mini } & 118 & Bad Data & & & \\
\hline S3 & 2203.445 & 11706.423 & 85 & & & & & \\
\hline \multicolumn{4}{|c|}{ MicroCAT TCP } & 14 & $4 / 20 / 2001$ & $5 / 5 / 2001$ & 14.6 & 1 \\
\hline \multicolumn{4}{|c|}{ Seamon-mini } & 22 & No Data & & & \\
\hline \multicolumn{4}{|c|}{ Mini-Starmon } & 32 & $4 / 20 / 2001$ & $5 / 5 / 2001$ & 14.6 & 1 \\
\hline \multicolumn{4}{|c|}{ MicroCAT TC } & 42 & $4 / 20 / 2001$ & $5 / 5 / 2001$ & 14.6 & 1 \\
\hline \multicolumn{4}{|c|}{ Seamon-mini } & 52 & Lost & & & \\
\hline \multicolumn{4}{|c|}{ Seamon-mini } & 62 & Lost & & & \\
\hline \multicolumn{4}{|c|}{ MicroCAT TC } & 72 & $4 / 20 / 2001$ & $5 / 5 / 2001$ & 14.6 & 1 \\
\hline \multicolumn{4}{|c|}{ Seamon-mini } & 77 & Lost & & & \\
\hline \multicolumn{4}{|c|}{ ADCP BB $300 / 4$ m } & 80 & $4 / 20 / 2001$ & $5 / 5 / 2001$ & 14.6 & 1 \\
\hline \multicolumn{4}{|c|}{ Seaguage SBE26 P } & 81 & $4 / 20 / 2001$ & $5 / 21 / 2001$ & 31 & 5 \\
\hline S2 & 2211.14 & 11703.49 & 72 & & & & & \\
\hline \multicolumn{4}{|c|}{ ADCP BB $300 \mathrm{kHz} / 4 \mathrm{~m}$} & 72 & $4 / 20 / 2001$ & $5 / 17 / 2001$ & 26.5 & 2 \\
\hline
\end{tabular}

These were among the largest internal waves ever observed in the ocean.

\section{B. A Basic Description of the Internal Wave Arrivals}

An overall impression of the scale of the internal solitons and when they occurred in relation to the local barotropic tide can be obtained by comparing the temperature fluctuations in the main thermocline with bottom pressure at mooring S7 (Fig. 3). The tide (red line) was mixed, diurnal dominant, with a large diurnal inequality and fortnightly variation. The tide was semidiurnal at neap, then became increasingly mixed and was purely diurnal during four to five days around the time of the spring tide. The principal tidal constituents from a harmonic analysis (Table II) bear this out: The strongest components were the $\mathrm{O} 1, \mathrm{~K} 1$, and $\mathrm{M} 2$ tides with amplitudes of 24,25 , and $13 \mathrm{~cm}$, respectively.

The temperature fluctuations at $140 \mathrm{~m}$ (blue line) provide a robust indicator of when the internal solitons passed by the mooring. The waves were all depression waves at the $350 \mathrm{~m}$ isobath, such that each passing wave caused a pronounced increase in temperature as the thermocline moved sharply down past the sensor. Each "spike" in Fig. 3 actually consisted of a packet of waves which are not visible when plotted on this scale (see next paragraph). The term "cluster" as used in this paper refers collectively to all the internal waves arriving on a certain phase of the barotropic tide, as indicated on the figure. Two such clusters of soliton packets were observed that had a counter-intuitive phase relationship with respect to the local fortnightly tidal beat. Recognizing that the waves were not locally generated, this relationship is described first and the phase issue will be revisited after the wave sources and propagation have been discussed. The local observation was that the solitons first appeared during the neap tide, for instance on April 23 for the first cluster and May 6 for the second. For the first cluster, the temperature fluctuations induced were nearly constant at around $5{ }^{\circ} \mathrm{C}$ across the entire cluster. For the second cluster, the temperature fluctuation increased from $5-9{ }^{\circ} \mathrm{C}$ from May 6-9, with the largest waves occurring 2-4 days into the cluster on May 8 and 9. Two days of somewhat smaller waves were observed on May 10-11, followed by larger $\left(\Delta \mathrm{T}>9^{\circ} \mathrm{C}\right)$ waves again on May 12 and 13. Both clusters were followed by a period of 4-5 days when no waves were observed. This period of no waves continued during the declining phase of the fortnightly envelope, and then the cycle was repeated. The largest amplitude waves in each cluster were $24 \mathrm{~h}$ apart, with a smaller amplitude wave in between. The smaller wave did not evenly split the time interval by $12 / 12$ hours but rather varied from wave-to-wave. The amplitude of the waves in cluster 2 was 


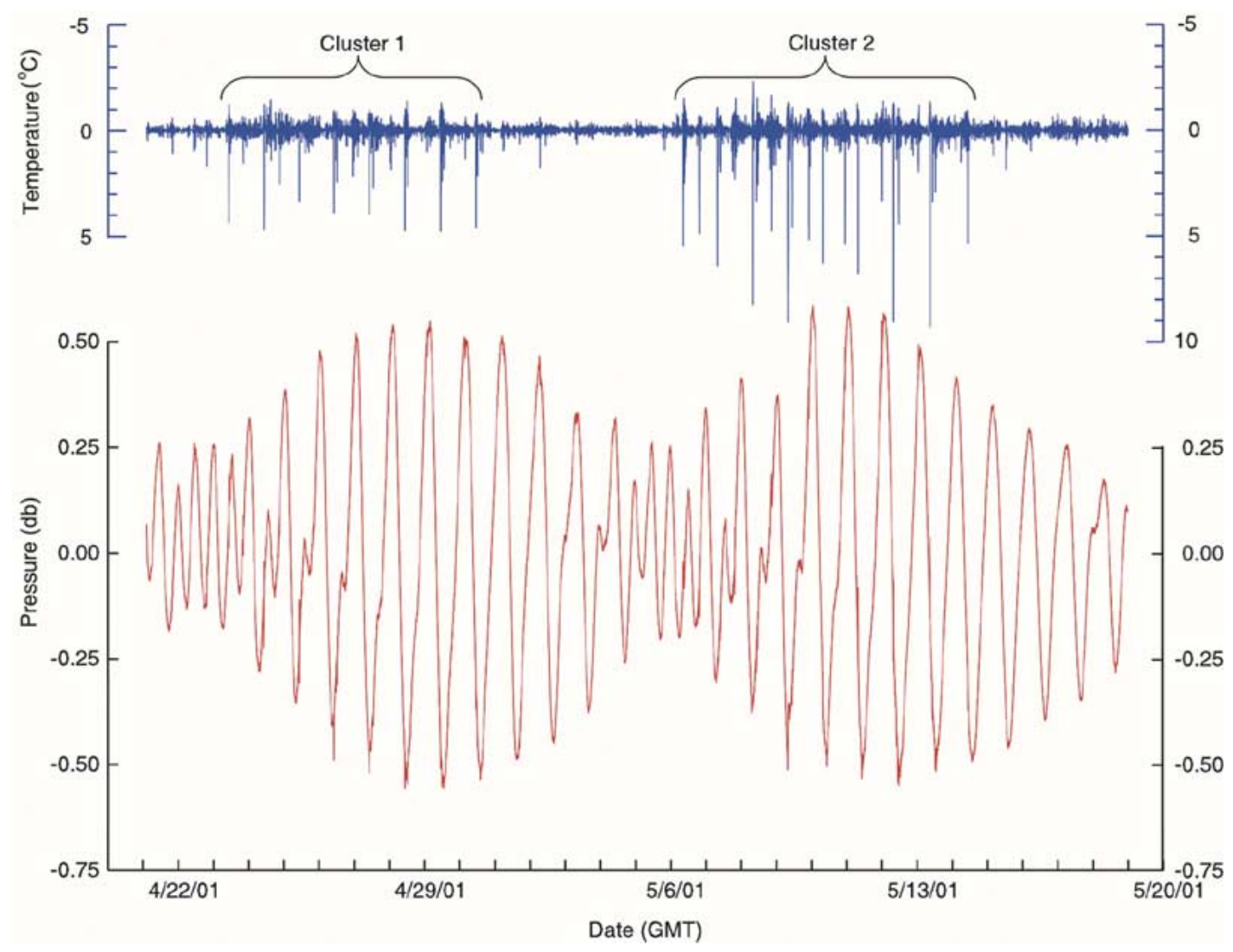

Fig. 3. De-meaned bottom pressure (red line) and high-pass filtered temperature fluctuations at $140 \mathrm{~m}$ (blue line) at site $\mathrm{S} 7$ on the $350 \mathrm{~m}$ isobath during the ASIAEX experiment. The blue "spikes" indicate thermocline depressions due to passing solitons. Note the time of soliton occurrence with respect to the local barotropic tide, as described in the text.

TABLE II

Barotropic Tidal Constituents From the Seagauge SBE26 Temperature/Pressure Recorder Deployed at ASiaEX Site S7. The Tides Were Mixed, Diurnal Dominant, As Shown in Fig. 3

\begin{tabular}{ccccccc}
\hline Tide & Rank & $\begin{array}{c}\text { Frequency } \\
(\mathbf{1} / \mathbf{h r})\end{array}$ & $\begin{array}{c}\text { Amplitude } \\
\mathbf{( m )}\end{array}$ & $\begin{array}{c}\text { Amp. Error } \\
(\mathbf{m})\end{array}$ & $\begin{array}{c}\text { Phase } \\
\text { (Greenwich) }\end{array}$ & $\begin{array}{c}\text { Phase Error } \\
\text { (Degrees) }\end{array}$ \\
K1 & 1 & .04178 & .246 & 0.1 & 171 & 2.3 \\
O1 & 2 & .03873 & .238 & .01 & 127 & 2.4 \\
M2 & 3 & .08051 & .130 & .005 & 5 & 2.1 \\
P1 & 4 & .04155 & .081 & .01 & 179 & 6.9 \\
S2 & 5 & .08333 & .049 & .005 & 15 & 5.7 \\
Q1 & 6 & .03722 & .031 & .01 & 120 & 18.6 \\
N2 & 7 & .07900 & .025 & .005 & 353 & 11.0 \\
K2 & 8 & .08356 & .013 & .005 & 37 & 21.4 \\
N01 & 9 & .04027 & .013 & .01 & 63 & 44.5 \\
J1 & 10 & .04329 & .012 & .01 & 249 & 47.8 \\
\hline
\end{tabular}

clearly greater collectively than cluster 1 . The cluster 2 waves caused thermal displacements about $3{ }^{\circ} \mathrm{C}$ greater than cluster 1 , which translates to more than $50 \mathrm{~m}$ of amplitude $(\eta)$ given the ambient stratification. The explanation for this is complex and somewhat speculative and is left to the discussion section.

The packet structure and timing of the wave arrivals over the continental slope can be seen in greater detail using daily stack plots of the temperature at mooring S7 (Fig. 4). This figure shows all the wave arrivals from cluster 2 (May 4-14), starting a few days before they commenced and continuing through the last of the large wave packets. For clarity, only the upper $250 \mathrm{~m}$ is shown, although in some cases (May 8-9) the waves extended beyond this depth. The properties of the cluster 1 waves (April 21-May 1) were similar except where noted.
Starting from the top of the plot, there were no high-frequency waves visible on May 4 and 5, although a strong semidiurnal tidal bore was clearly evident. The earlier bore had larger amplitude than the second one later in the day. The beginnings of a very small soliton were starting to show up on the second bore around 1900 on May 5. On May 6, the first large waves arrived in earnest. There were two packets per day, which shall henceforth be referred to as the "a" waves for the earlier packet and the "b" waves for the later one. The a-waves were stronger by far than the b-waves and quite different in character. For the a-waves the largest soliton was always in the lead with smaller peaks behind, sometimes rank-ordered and sometimes not. The b-waves usually consisted of only one large peak which grew out of the center of a packet rather than at the leading edge. The a-waves 

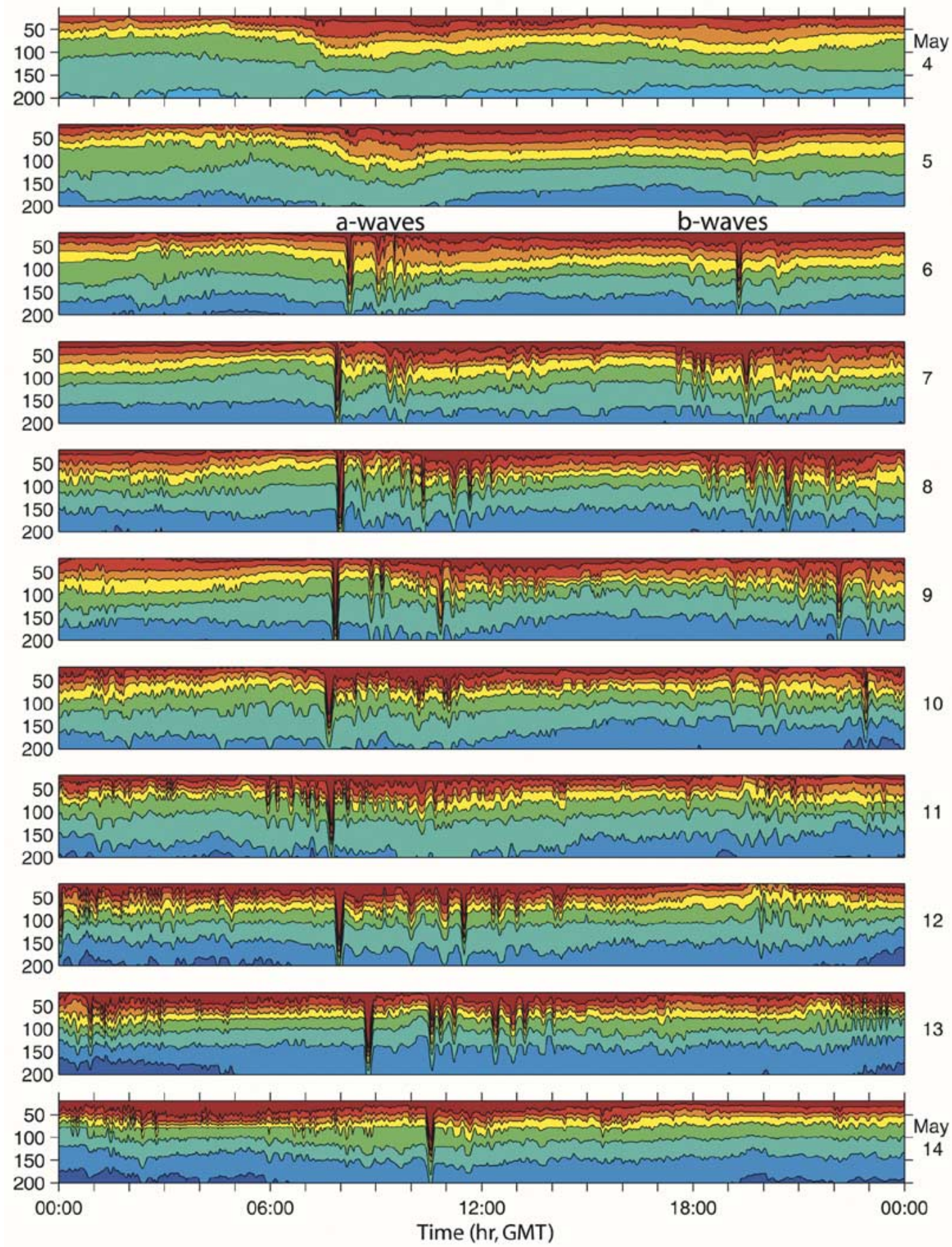

Fig. 4. Stack plot of temperature at mooring S7 on the $350 \mathrm{~m}$ isobath. The bottom $150 \mathrm{~m}$ are not shown to allow a clearer presentation of the internal wave structure. All available temperature sensors (Fig. 2, Table I) were used to construct the plot. Each panel is one day (May 4-14, 2001) from 0000 to $2400 \mathrm{~h}$.

were associated with the stronger of the two tidal bores, and the b-waves with the weaker bore.

The a-waves arrived diurnally with remarkable regularity, arriving about 0800 GMT every day. From May 6-9, the high-frequency wave amplitude increased and the amplitude of the associated tidal bore decreased, consistent with an increasing energy transfer from low-to-high frequencies [2]. The elapsed time between the first and second solitons in each packet also increased during this period (Table III) suggesting increasing wave dispersion with increasing amplitude. On May
11, five smaller waves appeared ahead of the main soliton. The velocity field (see propagation section) shows that these waves came from a different source and were interfering with the main wave packet. On May 13 and 14, the lead soliton arrived at S7 progressively later by 1 hour on May 13 and an additional 1.5 hour on May 14. This phenomenon was not observed in the cluster 1 waves and may be due to the passage of a tropical cyclone across the wave propagation path (see discussion section). The number of a-waves per packet varied from day to day but ranged from 3 to 9 (Table III). 
TABLE III

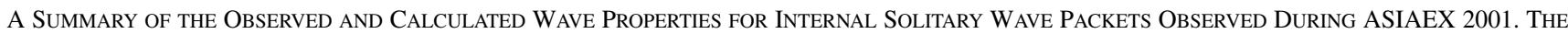
MaXimum Amplitude Was CAlCUlated Using THE DisPlacement OF THE $24^{\circ} \mathrm{C}$ ISOTHERM. THE WAVELENGTH IS THE DisTANCE BETWEEN THE LEADING

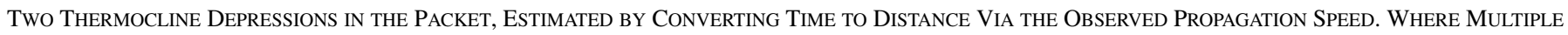
Values Appear, They Are the Distance Between the First and Second, Second and ThIRD PeaKs, And So on. The Half-Width Was LiKewise Estimated by Converting Time to Space Via the Wave Propagation SPeED

\begin{tabular}{|c|c|c|c|c|c|c|c|c|c|c|c|}
\hline Date & $\begin{array}{l}\text { \# Waves in } \\
\text { Packet }\end{array}$ & $\begin{array}{c}\text { Maximum } \\
\text { Amplitude } \\
\eta \\
(\mathrm{m})\end{array}$ & $\begin{array}{l}\text { Time between } \\
\text { Leading Peaks } \\
\quad(\min )\end{array}$ & $\begin{array}{c}\text { c (observed) } \\
\text { Non-Filterd } \\
(\mathrm{m} / \mathrm{s})\end{array}$ & $\begin{array}{c}\text { c (Two- } \\
\text { Layer } \\
\text { linear) } \\
(\mathrm{m} / \mathrm{s})\end{array}$ & $\begin{array}{c}\text { c (Two- } \\
\text { Layer } \\
\text { KdV) } \\
(\mathrm{m} / \mathrm{s})\end{array}$ & $\begin{array}{c}\text { c (Two- } \\
\text { Layer } \\
\text { EKdV) } \\
(\mathrm{m} / \mathrm{s})\end{array}$ & $\begin{array}{c}\lambda \\
\text { (wavelength) } \\
(\mathbf{k m})\end{array}$ & $\begin{array}{l}\text { L (half- } \\
\text { width) } \\
\text { Observed } \\
\text { (m) }\end{array}$ & $\begin{array}{l}\text { L (half-width) } \\
\text { Two-Layer } \\
\text { KdV } \\
\text { (m) }\end{array}$ & $\begin{array}{l}\text { L (half-width) } \\
\text { Two-Layer } \\
\text { EKdV } \\
\text { (m) }\end{array}$ \\
\hline \multicolumn{12}{|c|}{ 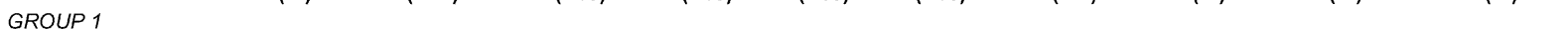 } \\
\hline April 23a & 2 & 68 & 50 & 1.50 & 1.16 & 1.63 & 1.38 & 4.8 & 690 & 284 & 566 \\
\hline April $24 a$ & 2 & 74 & 90 & 1.46 & 1.16 & 1.68 & 1.38 & 8.2 & 720 & 270 & 640 \\
\hline April $25 a$ & 2 & 62 & 98 & 1.26 & 1.16 & 1.59 & 1.37 & 7.4 & 580 & 296 & 522 \\
\hline April 26a & 3 & 45 & 85 & 0.91 & 1.16 & 1.47 & 1.34 & $4.7 ; 2.1$ & 790 & 362 & 502 \\
\hline April 27a & 4 & 58 & 84 & 0.83 & 1.16 & 1.56 & 1.37 & $4.1 ; 2.2 ; 1.7$ & 380 & 306 & 506 \\
\hline April 28a & 1 & 65 & NA & 1.09 & 1.16 & 1.61 & 1.38 & & 400 & 290 & 538 \\
\hline April 29a & 1 & 70 & NA & 1.18 & 1.16 & 1.65 & 1.38 & & 720 & 278 & 584 \\
\hline April 30a & 1 & 59 & NA & 1.13 & 1.16 & 1.57 & 1.37 & & 590 & 304 & 510 \\
\hline April 22b & 1 & 38 & NA & 1.48 & 1.16 & 1.43 & 1.32 & & 900 & 378 & 494 \\
\hline April 23b & 1 & 29 & NA & 1.52 & 1.16 & 1.36 & 1.29 & & 920 & 434 & 524 \\
\hline April 24b & 1 & 42 & NA & 1.21 & 1.16 & 1.45 & 1.33 & & 950 & 362 & 488 \\
\hline \multicolumn{12}{|l|}{ GROUP 2} \\
\hline May 6a & 2 & 88 & 49 & 1.46 & 1.16 & 1.77 & NA & 4.3 & 570 & 248 & NA \\
\hline May $7 a$ & 3 & 110 & 90 & 1.33 & 1.16 & 1.93 & NA & $7.3 ; 1.8$ & 380 & 222 & NA \\
\hline May $8 a$ & 4 & 135 & 144 & 1.26 & 1.16 & 2.1 & NA & $10.6 ; 4.0 ; 2.1$ & 570 & 200 & NA \\
\hline May 9a & 2 & 142 & 180 & 1.23 & 1.16 & 2.15 & NA & 13.1 & 510 & 196 & NA \\
\hline May $10 a$ & 3 & 80 & 153 & 1.47 & 1.16 & 1.72 & 1.39 & $13.6 ; 4.4$ & 650 & 260 & 828 \\
\hline May $11 a$ & * & 88 & & 1.14 & & 1.77 & NA & & 470 & 248 & NA \\
\hline May $12 a$ & 4 & 95 & 122 & 1.49 & 1.16 & 1.82 & NA & $11.0 ; 5.1 ; 3.0$ & 670 & 238 & NA \\
\hline May $13 a$ & 7 & 95 & 108 & 1.84 & 1.16 & 1.82 & NA & $11.9 ; 1.7 ; 2.6$ & 850 & 238 & NA \\
\hline May $14 a$ & 1 & 73 & NA & 1.83 & 1.16 & 1.67 & 1.38 & & 800 & 274 & 624 \\
\hline May 6b & 1 & 62 & NA & 1.66 & 1.16 & 1.59 & 1.37 & & 550 & 296 & 524 \\
\hline May $7 b$ & 1 & 50 & NA & 1.66 & 1.16 & 1.51 & 1.35 & & 860 & 330 & 490 \\
\hline May $8 b$ & 1 & 65 & NA & 1.68 & 1.16 & 1.61 & 1.38 & & 970 & 290 & 540 \\
\hline May 9b & 1 & 62 & NA & 1.50 & 1.16 & 1.59 & 1.37 & & 510 & 296 & 522 \\
\hline May $10 \mathrm{~b}$ & 1 & 47 & NA & 1.19 & 1.16 & 1.49 & 1.34 & & 620 & 340 & 488 \\
\hline May $11 \mathrm{~b}$ & 1 & 48 & NA & 1.28 & 1.16 & 1.5 & 1.35 & & 430 & 338 & 488 \\
\hline
\end{tabular}

The first of the b-waves arrived at around 1900 on May 6 , 11 hours after the lead a-wave of the same day. The b-wave amplitudes, including the largest peak, were uniformly smaller than the a-waves (Table III). Unlike the a-waves, the b-waves arrived about an hour later each day, approximately like the M2 tidal progression. (Note that the b-waves wrap around from the end to the beginning of the plot on May 12). By the end of the record, the a-waves nearly merged with the lagging $b$-waves from the cycle before, but then a period of no waves began and this never actually happened. Interfering waves must therefore arrive from a different source.

Several unusual features of this plot might be explained by the structure of the tides in the generation region. The data suggest a diurnal inequality in the tides at the generation site, with the a-waves generated on the stronger of the two semidiurnal pulses. The a-waves also seem phase-locked to the nonprogressing diurnal tide while the $b$-waves were in tune with the semidiurnal tide. This may also be a feature of the generating tide. The remarkable regularity with which the waves arrived suggests they were riding on the tidal bore over most of the propagation path. The waves might thus correctly be referred to as solibores [42]. This issue is examined in greater detail in subsequent sections of the paper.

\section{Wave Transformation in Shallow Water}

At mooring S5 (Fig. 5) the a-waves began arriving around noon and the b-waves at 1900 . Tidal bores were again evident not only on May 4-6, but again during May 10-14. Since this second bore was diurnal and was not observed at mooring S7, it was likely generated locally over the continental slope between moorings S7 and S5. It did not appear until the local tide approached the spring tide. In a companion paper, the local generation of internal tidal bores has been analyzed in greater detail [2]. They found that the critical bottom slope for diurnal tide generation over the observed buoyancy frequencies varied between 0.15-0.40, and that this range of slopes was found over a broad area of the bottom near mooring site S6. Thus, these results are consistent with the local generation of a diurnal internal tide between moorings S7 and S5. These large amplitude internal oscillations at tidal frequencies were also evident in the ASIAEX SeaSoar data near moorings S5 and S4 [3].

Like at mooring S7, the solitons at S5 were all waves of depression causing very large increases in temperature at each depth. During May 6-9, the amplitudes of the lead solitons in the a-waves was smaller at S5 than at S7 due to the presence of the bottom at $200 \mathrm{~m}$. On May 6, 8, and 9, the lead soliton in the a-wave packets had split into two smaller peaks at S5, possibly due to wave fission [32], [43]. There was a pronounced change in the a-waves between May 6-9 versus May 10-13. The later waves were smeared out by advection due to the local internal tide and were much broader than the May 6-9 waves. The b-wave packets at S5 arrived about an hour later each day similar to the b-waves at mooring S7. The b-wave solitons also equilibrated in amplitude somewhat, but the central peak persisted for 

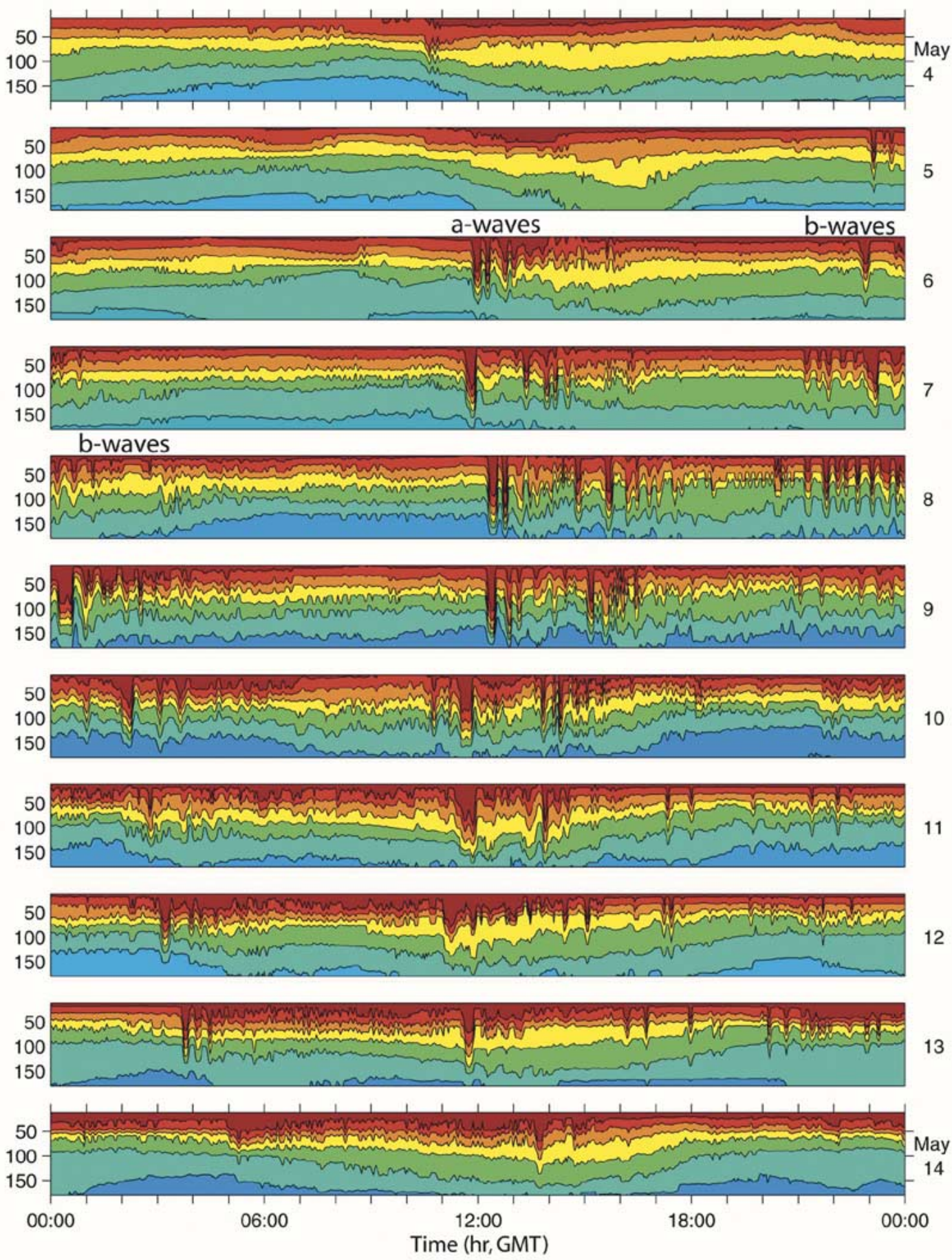

Fig. 5. As in Fig. 4 but for mooring S5 on the $200 \mathrm{~m}$ isobath. The entire water column is shown.

some packets (May 10-12). No wave splitting was observed in the b-waves. This was likely because the wave amplitude was so much smaller to begin with in the b-waves than the a-waves that it was less impacted by the bottom at S5. By May 15, all the solitons at S5 had disappeared.

The wave field was radically altered by the time it reached site $\mathrm{S} 4$ on the $120 \mathrm{~m}$ isobath (Fig. 6). An important thing to notice in this plot is the appearance of elevation waves (indicated by the magenta underscores) which lifted bottom water up near the surface causing sudden drops, rather than elevations, in temperature at mid-depth. As described in the introduction, these eleva- tion waves are expected when the upper layer thickness exceeds the lower layer thickness. Clearly this situation developed several times during the experiment at site S4. Multiple processes contributed to the formation of elevation waves, some of which are described below.

There were no waves at all arriving on May 4 and 5 as the b-wave from late in the day on May 5 at S5 did not arrive at S4 until early May 6. The pronounced tidal bore of May 4 and 5 propagated all the way up the shelf without spawning any new waves, apparently not quite strong enough to do so anywhere along its path. The stronger a-waves arrived at S4 at 

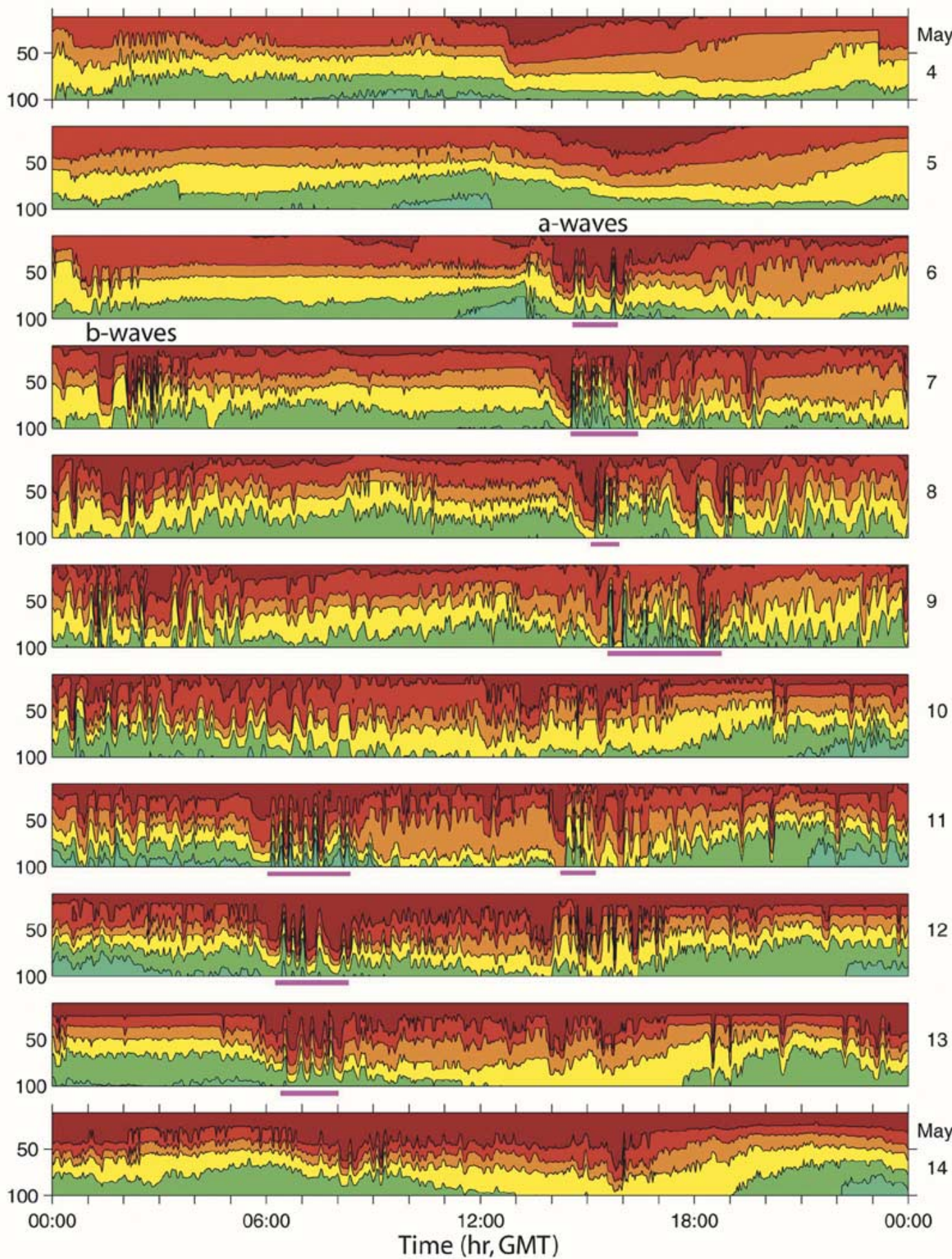

Fig. 6. As in Fig. 4 but for mooring S4 on the $120 \mathrm{~m}$ isobath. The top $100 \mathrm{~m}$ are shown. The magenta underbars indicate regions where elevation waves have formed.

about 1400 on May 6-9 but took on a very different form with respect to mooring S5 (Fig. 5). The huge lead solitons at S7, which split into two waves at S5, formed broad thermocline depressions at S4. This is because the soliton peaks were pushed up by the shoaling bottom and became broader also, since the soliton width is inversely proportional to its vertical displacement. An explanation of the wave widening and deformation in terms of linear wave speed changes for a thermocline transition from near-surface to near-bottom depth can be found in the literature [37], [44]. Essentially, the nonlinear processes no longer counteract the varying linear wave speed computed throughout the wave to allow a wave of permanent form, and the trough and shoulders of the wave diverge as the bathymetry shoals. In the wake of this broad lead depression, many packets of elevation waves developed. An outstanding example of this would be on May 7 between 1400 to $1700 \mathrm{~h}$. The elevation waves were very narrow, closely spaced, and approximately equal in height. Some of the waves contained water which was anomalously cold. This water was likely lifted up from very near the bottom (below the deepest sensors). 
During May 10-13, the internal tide created a period when the thermocline was very close to the bottom from roughly 0600 to 1800 h. During this time, packets of elevation waves formed both near the front and back of the bore, for example during 0600-0900 and 1400-1700 hours. During the high-side of the cycle from 1800 to 0600 the next day, depression solitons formed. This is easily explained via the well known theory that when the upper-layer depth is thinner than the lower-layer depth (the usual deep water case) depression waves form, but when the upper layer is thicker than the lower layer, elevation waves form. Mathematically this occurs when the nonlinear parameter $\alpha$ changes sign [7]. Clearly, the criterion for elevation waves was met during 0600-1800 hours when the thermocline was nearly on the bottom. At other times the thermocline was slightly above mid-depth and the usual depression waves formed. An important point to emphasize is that the "critical location" where $\alpha$ goes to zero is dynamic rather than static, and is not fixed to a particular isobath. The upper layer thickness is impacted by mesoscale variability, the internal tide, and indeed the internal waves themselves which sometimes cause broad regions of thermocline depression as they widen and run together. Elevation waves can then develop out of these regions.

Mooring S3 was located on the $80 \mathrm{~m}$ isobath $18 \mathrm{~km}$ shoreward of S4 on the continental shelf. This mooring was lost to fishing activity during the second half of the ASIAEX experiment, and thus plots similar to Figs. $4-6$ are not available. By studying the S3 data for the cluster 1 waves (not shown) however we can say that the waves were highly attenuated by the time they reached S3. The waves there were a mixture of elevation solitons and oscillations which resembled ordinary linear internal waves. The WHOI Low-Cost (LOCO) moorings were set in the region between S4-S2 and provide a more detailed look at wave evolution in this region. This is one subject of another manuscript in this volume [2].

\section{Wave Propagation}

The uniqueness of each wave packet was an asset in terms of tracking its propagation from one mooring to the next through the array. Even so, not all packets could be accurately tracked, since they changed too much between moorings. Moorings S7, S6, and S5 were used for this exercise since the bottom interaction effects were not too severe. Mooring S6 was a velocity-only mooring and is thus not shown in the temperature time series (Figs. 4-6) but was used in tracking the velocity peaks. The elapsed time between moorings was easily determined from the time series (compare for instance a-wave arrivals in Figs. 4 and 5), however to compute the phase speed the geometry of the moored array and the direction the waves were propagating toward must also be accounted for. The waves were not propagating with crests normal to the moored array line but rather at some angle with respect to it. This angle was determined for each wave using the orbital velocities from the time series and SAR images when available [45].

The inferred propagation speeds from peak tracking showed a range of speeds from 0.83 to $1.84 \mathrm{~m} \mathrm{~s}^{-1}$ with a mean of about

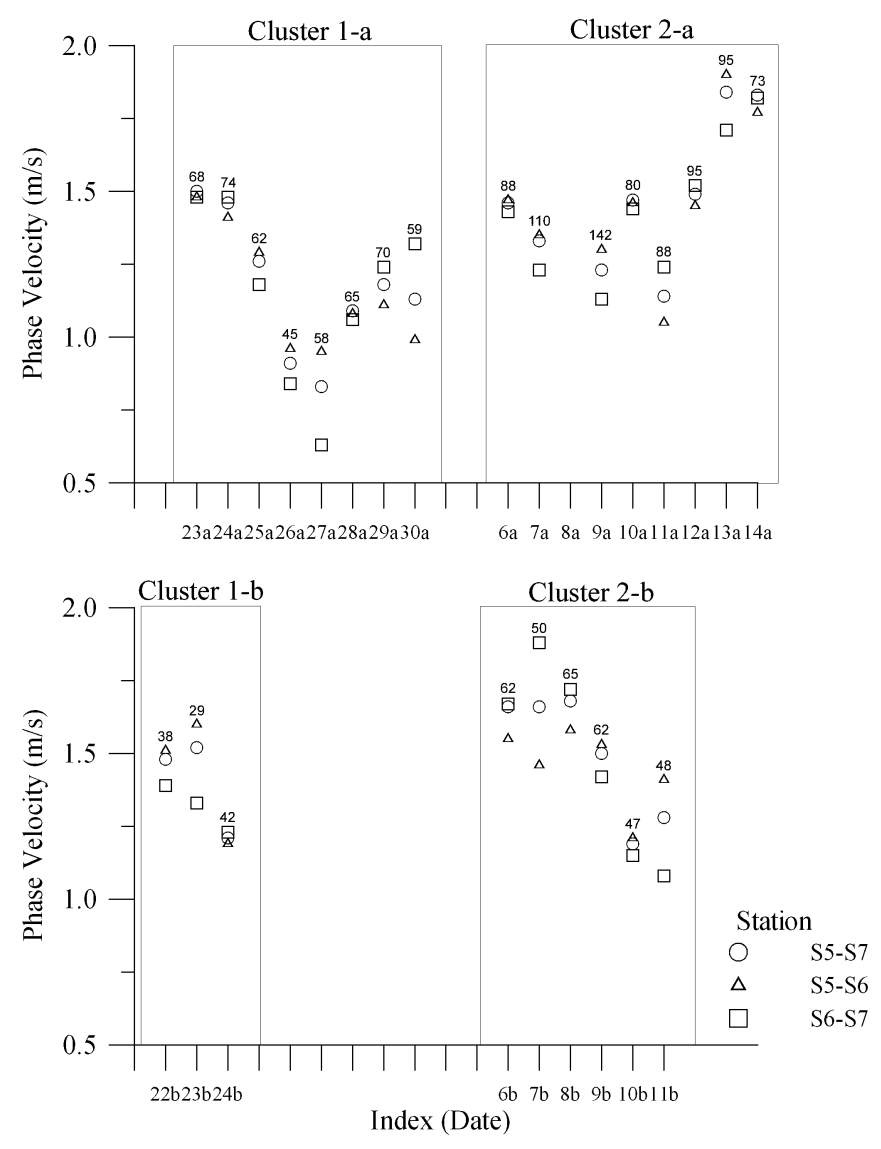

Fig. 7. Observed phase speed of the ASIAEX internal solitons computed by tracking the wave packet velocity structure between moorings S7 and S5 (circles), S6 to S5 (triangles), and S7 to S6 (squares). The a-waves are plotted in the top panels and the b-waves at the bottom, both against the same time axis. The observed wave amplitude $(\mathrm{m})$ at mooring $\mathrm{S} 7$ is given by the number above each day. The methodology is described in detail in the text.

$1.25 \mathrm{~m} \mathrm{~s}^{-1}$ (Fig. 7, Table III). The consistency between moorings in Fig. 7 was good, indicating that bottom interaction did not alter the wave speed very much in this depth range. However, there was no correlation at all between the nonlinear wave amplitude (indicated by the number above each column) and the phase speed. This again indicates that all the waves were being advected by the internal tide. The cluster a- and b-waves both showed a slight increase in phase speed with time. This was perhaps due to increasing stratification in the SCS basin during April and May, although there is little data to support this notion. Both sets of type a-waves displayed a minimum in the phase velocity in the middle of the cluster, while the phase speed decreased across each b-wave cluster. These small deviations from the mean phase speed were weakly correlated with nonlinear wave amplitude for clusters 1-a and 2-b, but were not correlated with wave amplitude at all for clusters 2-a and 1-b. The reason for these deviations is thus not obvious but may be due to some nuance in the fortnightly tidal cycle at the generation site.

The phase speeds were also computed theoretically using the two-layer and continuously stratified KdV and EKdV formulations. The density stratification and buoyancy frequency profiles used in the calculations were obtained via a CTD cast at each mooring site [Fig. 8 (top)]. For the two-layer studies, a fit to the 

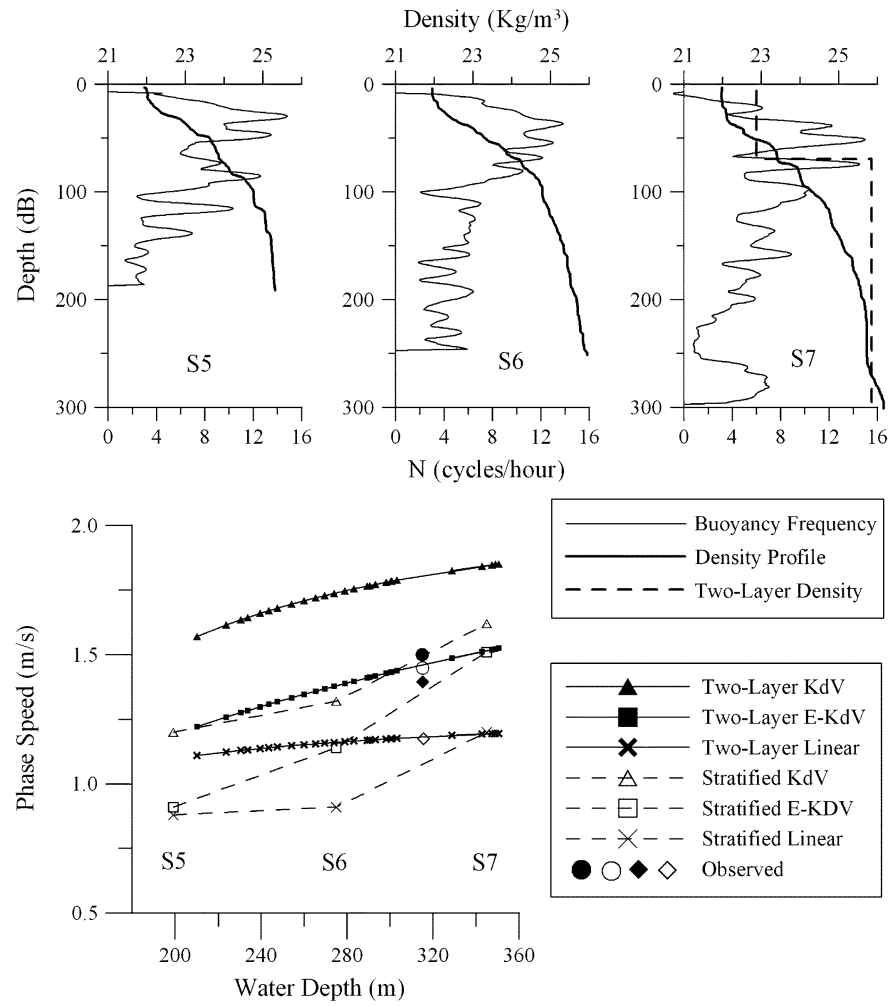

Fig. 8. Observed and theoretical phase speed for the nonlinear internal waves observed in the ASIAEX region. The theoretical curves are identified as in the legend, calculated using the mean density and Brunt-Vaisala frequencies plotted at the top. The observed symbols are the averaged values from Fig. 7. From bottom to top, the symbols represent the mean phase speeds for cluster 1-a (open diamond), cluster 1-b (solid diamond), cluster 2-a (open circle) and cluster 2-b (solid circle).

$350 \mathrm{~m}$ profile was used as the deeper data there were most representative of the stratification along the entire wave propagation path.

The wave amplitude (or "displacement") is a necessary input for all the theoretical calculations. Traditionally, this has been computed in the literature as

$$
\eta^{\prime}(t)=\frac{T^{\prime}(t)}{\partial T / \partial z}
$$

where $T^{\prime}$ is computed using the high-passed (IW) time series and the vertical gradient $\partial \mathrm{T} / \partial \mathrm{z}$ using some form of smoothed series similar to the ASIAEX low-passed time series. This method failed for the ASIAEX data, however, because the waves were so large that the surface water was depressed down past many of the sensors. Once this happened, the $\mathrm{T}^{\prime}$ fluctuation looked the same for all the waves and did not represent an accurate measure of the wave amplitude. Alternatively, the wave amplitude was computed as the displacement of the $24^{\circ} \mathrm{C}$ isotherm as each soliton passed by mooring $\mathrm{S} 7$. This was made possible by the close thermometer spacing. The undisturbed depth of this isotherm was about $50-60 \mathrm{~m}$ in the lower thermocline and it did not surface during the experiment. This measure is likely an underestimate of the true wave amplitude but provides a good measure of the relative amplitude of the arriving waves. For example, the amplitude in the May 8 wave was $138 \mathrm{~m}$ using the displacement of the $24{ }^{\circ} \mathrm{C}$ isotherm but exceeded $200 \mathrm{~m}$ at $140 \mathrm{~m}$ depth using (1). For the phase speed calculations, the relative speed of the waves was of interest, so the amplitudes from the displacement of the $24^{\circ} \mathrm{C}$ isotherm were used.

The results (Table III; Fig. 8 (bottom)) show the difficulty of simulating these very large amplitude nonlinear waves using the conventional approaches. The two-layer KdV theory produced phase speeds that were too high and half-widths that were too small by a factor of two. The two-layer EKdV theory returned much better agreement with the observations for both the width and phase speed for waves of moderate amplitude, but broke down completely for the very large waves (greater than $88 \mathrm{~m}$ ). Some overlap in the observed vs. calculated phase speeds is evident, however it seems fair to say that collectively, the EKdV theory provided a better estimate of both the soliton widths and phase speeds than the KdV (Table III; Fig. 8). A new theoretical approach is needed for the very large waves. The error in the data is too great to discern between the two-layer and continuously stratified EKdV case, likely due to the very sharp thermocline which closely approximated a two-layer system at $350 \mathrm{~m}$ depth and deeper. The theory indicates that the waves were already starting to slow down between S7 and S5 although this was not obvious observationally (Fig. 7). Their propagation speed across the South China Sea's northeast deep basin was likely closest to the speed at mooring S7, where both the EKdV models and the observations indicated a mean phase speed of about $1.5 \mathrm{~m} \mathrm{~s}^{-1}$. This value will be used subsequently in the discussion section to estimate the propagation time from the generation site.

\section{E. The Generation Site}

A well known property of the highly nonlinear internal solitary waves is that they propagate in the direction of the upper layer velocity [7]. The waves make a very obvious signal in the high-passed data with the velocity maximum typically a factor of ten or more above the background noise. These characteristics were exploited to set up an automated procedure to study the strength of the waves and their direction of propagation, and using reverse ray tracing, to determine their most likely point of origin. For this exercise, the data from mooring IW1 deployed at $21^{\circ} 02^{\prime} \mathrm{N}, 117^{\circ} 12^{\prime} \mathrm{E}$ during April 2000 was added to the mix, since it was closer to Dongsha Island and also contained many soliton packets. The analysis depth was chosen for good signal to noise ratio and was $100 \mathrm{~m}$ for IW1, $97 \mathrm{~m}$ for S7, and $60 \mathrm{~m}$ for S6, S5, and S4. For each mooring, the vector speed and direction were computed above some threshold value designed to include only the solitons and exclude the background noise. The high-passed filtered data were used for the screening process and the unfiltered data were used in the calculation, that is, advection by the large-scale flow was included. Histograms of speed and direction were then constructed using all the data meeting the prescribed criteria (Fig. 9). These histograms are very revealing and provide statistical explanations for many features seen in the data.

A threshold of $|50| \mathrm{cm} \mathrm{s}^{-1}$ for the u-component at S7 and IW1 excluded all but the largest solitons [Fig. 9(a)]. The S7 data had a single peak toward $282^{\circ}$ true north ( $\left.{ }^{\circ} \mathrm{T}\right)$, which points directly at the Batan Islands in the Luzon Strait. Thus, all the largest solitons originated from near these islands. The speed histogram shows that the very large waves were somewhat 

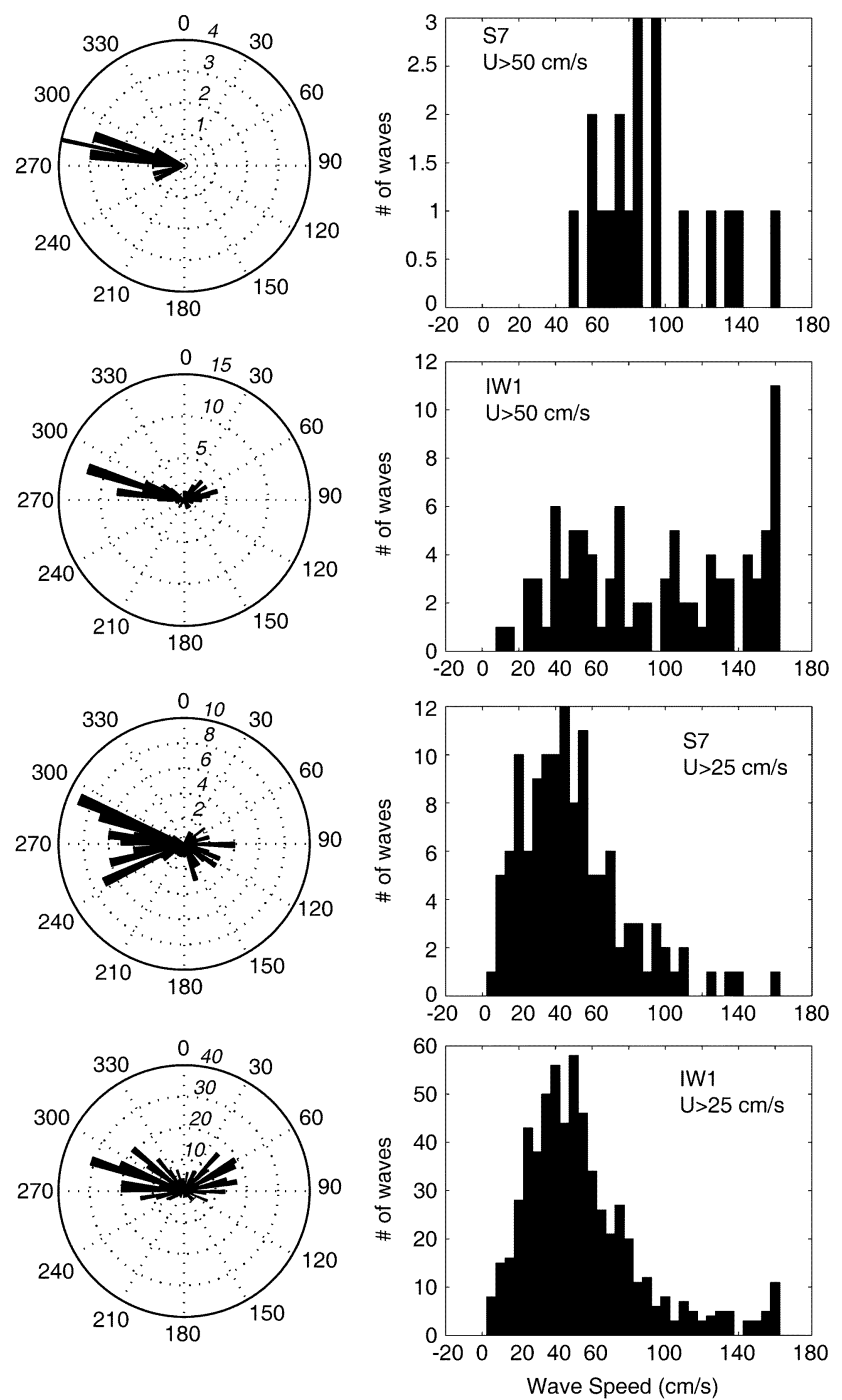

Fig. 9(a)-(d). Histograms of current speed and direction for all solitons having greater than a certain threshold speed in the east-west (u) velocity component. The u-component was used to screen the data however the values on the x-axis denote the total vector velocity in the wave. The number of waves having that velocity is indicated by the length of the bars. The number of occurrences in the polar direction histograms is indicated by the dotted circles labeled in italics. From top to bottom, the four panels are for: (a) S7, $97 \mathrm{~m}, \mathrm{u}>50 \mathrm{~cm}$ $\mathrm{s}^{-1}$; (b) IW1, $100 \mathrm{~m}, \mathrm{u}>50 \mathrm{~cm} \mathrm{~s}^{-1}$; (c) $\mathrm{S} 7,97 \mathrm{~m}, \mathbf{u}>25 \mathrm{~cm} \mathrm{~s}^{-1}$; and (d) IW1, $100 \mathrm{~m}, \mathrm{u}>25 \mathrm{~cm} \mathrm{~s}^{-1}$.

anomalous: Waves with speeds below $100 \mathrm{~cm} \mathrm{~s}^{-1}$ were much more common than waves with speeds over $100 \mathrm{~cm} \mathrm{~s}^{-1}$. At IW1, there were many more solitons spread over a range of speeds, with a strong direction peak again appearing at $282^{\circ} \mathrm{T}$. At this site however there were also some waves heading toward the northeast. To try and quantify this further, threshold was lowered to $25 \mathrm{~cm} \mathrm{~s}^{-1}$ which included many more waves [Fig. 9(c) and (d)]. This revealed more waves at S7 propagating in other directions, and a clearly bimodal direction histogram at IW1 with peaks at $282^{\circ} \mathrm{T}$ and $55^{\circ} \mathrm{T}$. The waves in this second peak were coming from the southwest $\left(235^{\circ} \mathrm{T}\right)$, which points directly to Dongsha Island. Thus, all the largest waves observed at S7 and IW1 were coming from the Luzon Strait, while many of the smaller waves were coming from around Dongsha.
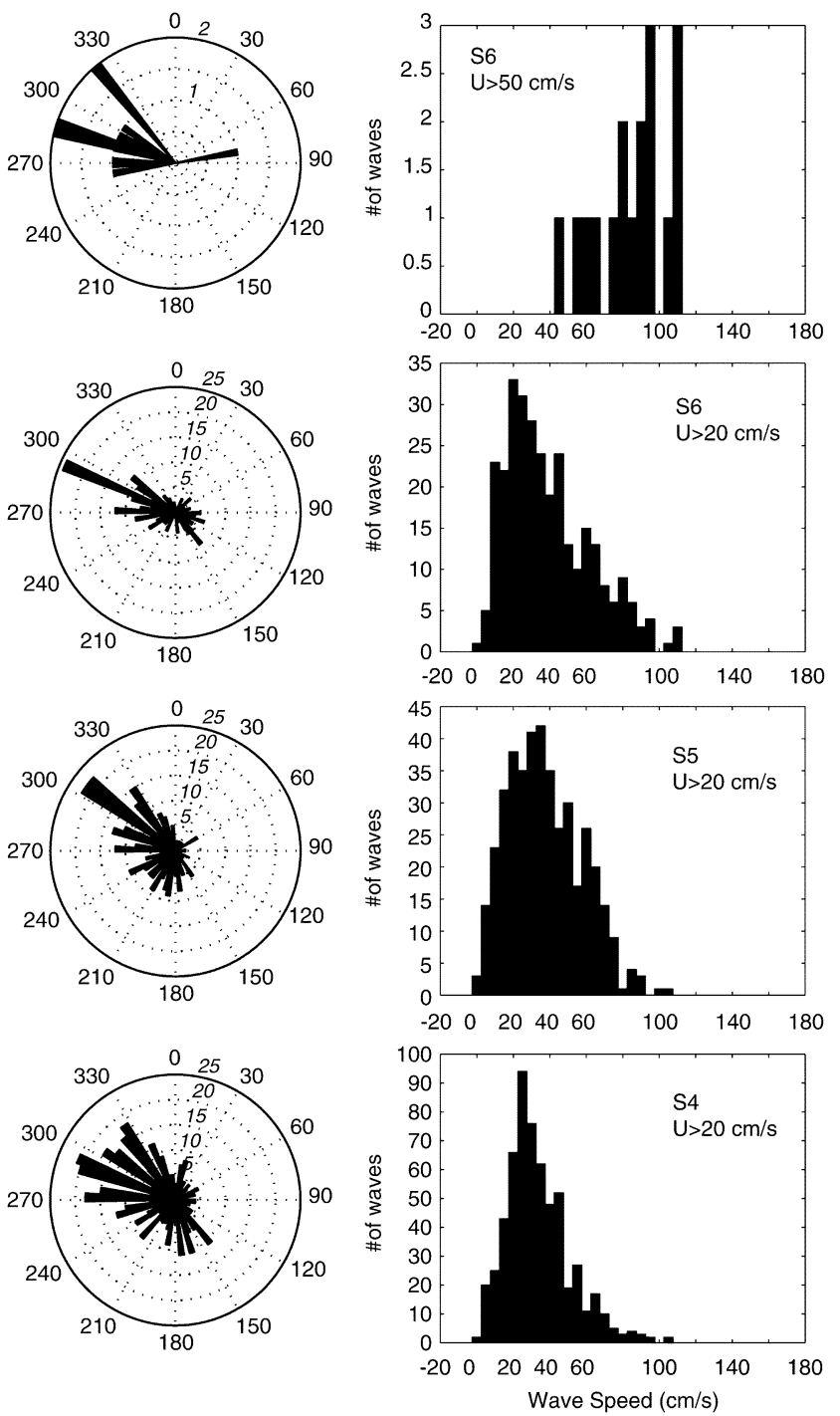

Fig. 9(e)-(h). As in Fig. 7(a)-(d), except for different moorings, depths, and threshold velocities. From top to bottom, the four panels are for: (e) $\mathrm{S} 6,60 \mathrm{~m}, \mathrm{u}>50 \mathrm{~cm} \mathrm{~s}^{-1}$; (f) $\mathrm{S} 6,60 \mathrm{~m}, \mathrm{u}>20 \mathrm{~cm} \mathrm{~s}^{-1}$; (g) $\mathrm{S} 5,60 \mathrm{~m}, \mathrm{u}>20 \mathrm{~cm} \mathrm{~s}^{-1}$; and (h)S $4,60 \mathrm{~m}, \mathrm{u}>20 \mathrm{~cm} \mathrm{~s}^{-1}$. Lower thresholds had to be used in shallower water as the soliton amplitude decreased.

This result is visually supported by the synthetic aperture radar (SAR) imagery (Fig. 10) which clearly shows this island refraction phenomenon. Referring back for a moment to Fig. 4, the waves leading the largest soliton on May 11 were in fact among those propagating toward $55^{\circ} \mathrm{T}$, and were thus coming from around Dongsha Island and were not part of the May 11 trans-basin packet.

The wave histograms from shallower water [Fig. 9(e)-(h)] provide clues to what is happening there. At S6, the large waves were still heading WNW but slightly more toward the north toward $292^{\circ} \mathrm{T}$. This difference is ascribed to refraction by the shoaling bottom and can also be observed in the curvature of the wave fronts as seen in Fig. 10 and other SAR images [45]. A single large wave at S6 appears to have been reflected. Moving into still shallower water, the waves fill up the left hemisphere of the direction histograms bounded by a line between 150 to $330^{\circ} \mathrm{T}$, approximately normal to the continental shelf break. This is due to a combination of reflection, refraction, and 


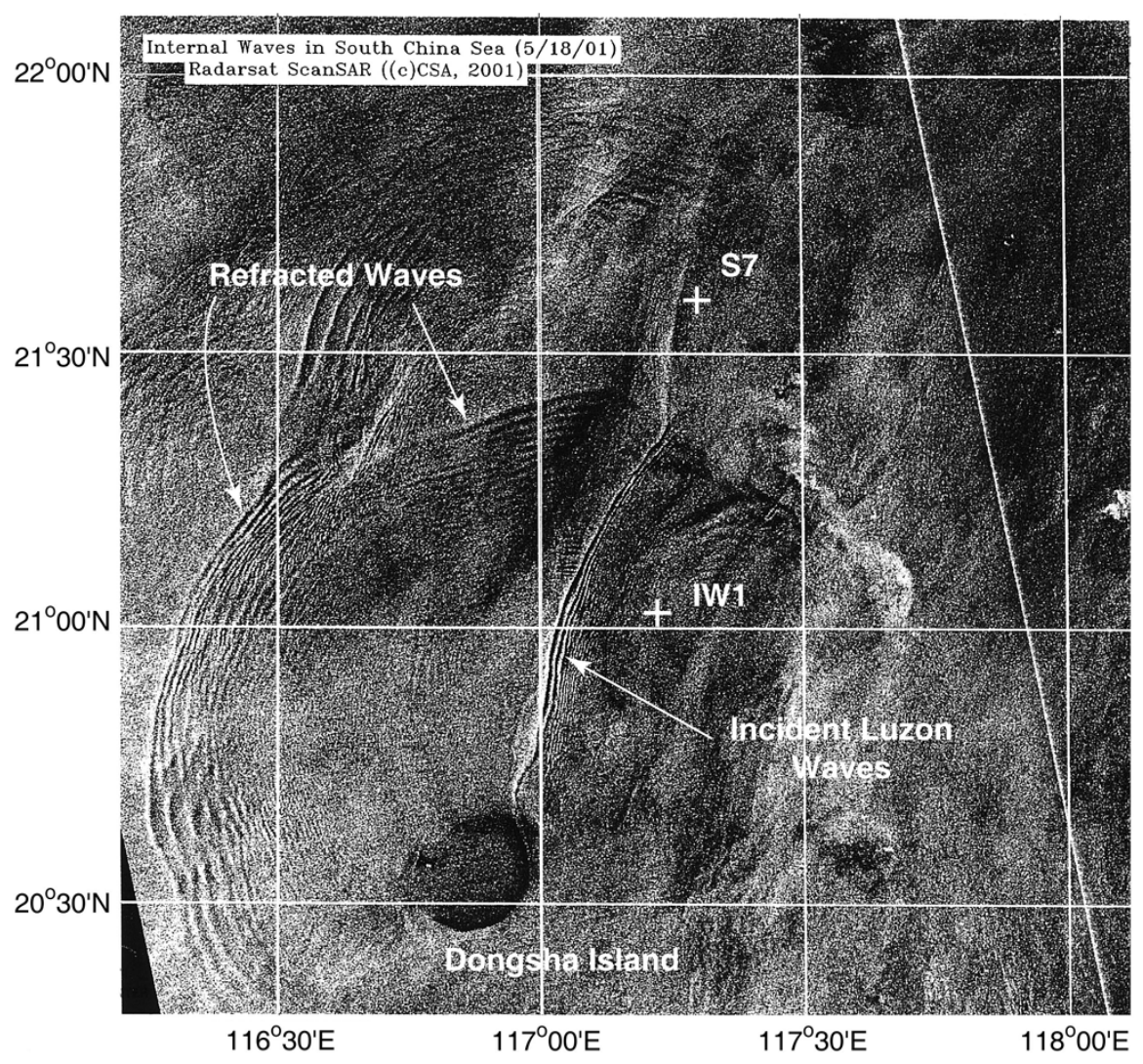

Fig. 10. Synthetic aperture radar (SAR) image from May 18, 2001 showing incident and refracted waves around Dongsha Island near the ASIAEX region. The moorings IW1 from April 2000 and S7 from April-May 2001 are also indicated.

alongshore advection by the mean flow, which was toward the southwest at all times. Based on these results, it is easy to see how the wave packet structure quickly becomes very complicated in the vicinity of the shelf break.

\section{F. Modal Structure of Wave Packets}

While each wave packet was unique with respect to the number, spacing, and amplitude of the solitons it contained, certain features of the waves were robust from packet-to-packet and are described here using two examples, one for depression waves at S7 [Fig. 11(a)] and the other for elevation waves at S4 [Fig. 11(b)]. There were four clear solitons in the May 8 packet [Fig. 11(a)] before the background noise level was reached. The solitons in this packet were approximately rank-ordered, i.e., decreasing in amplitude and period from front to back. About $2.3 \mathrm{~h}$ elapsed between the first and second peaks, $1.0 \mathrm{~h}$ between the second and third, and $0.5 \mathrm{~h}$ between the third and fourth. The large elapsed time between the first two waves was typical of all the a-waves and indicates significant dispersion, suggesting the waves traveled a great distance. This time is much greater than that of previously observed waves on continental shelves where it is typically only $15-20 \mathrm{~min}$ for waves generated close by [24], [46]. For the Sulu Sea it was typically about 40-50 min for waves that had been traveling for two days across the sea [26]. The waves left a small but discernable trailing thermocline depression in their wake, also consistent with previous observations and theory [32], [33].
The zonal and vertical velocity components [Fig. 11(a)] show the strength, direction of propagation, and modal structure of the waves. For clarity, only the u-component is shown since it contained most of the velocity and the v-component exhibited similar vertical structure. These were classic mode-1 waves, with opposing velocities in the upper and lower layers and a node somewhere between $90-150 \mathrm{~m}$ depth, apparently closer to $150 \mathrm{~m}$ given the weaker currents there. For the leading, largestamplitude wave, the $(\mathrm{u}, \mathrm{v})$ velocities in the upper layer were $(-125,95) \mathrm{cm} \mathrm{s}^{-1}$ respectively indicating propagation toward $307^{\circ}$ true north (WNW). The opposing lower-layer velocities $(\mathrm{u}, \mathrm{v})$ were weaker at $(60,-100) \mathrm{cm} \mathrm{s}^{-1}$ and spread over a broader depth range than the upper layer velocities. There was a sharp negative (downward) vertical velocity $\left(-60 \mathrm{~cm} \mathrm{~s}^{-1}\right)$ just ahead of the thermocline depression and a positive (upward) vertical velocity $\left(40 \mathrm{~cm} \mathrm{~s}^{-1}\right)$ behind it. In between, over the width of the pulse, there was a slower upward velocity of about $10-15 \mathrm{~cm} \mathrm{~s}^{-1}$. The maximum horizontal velocities were also observed during this time, between the two vertical pulses. This velocity structure agrees well with the theoretical expectation for internal solitary waves [7], and was consistent among the leading waves in the other packets as well. The third and fourth peaks arriving at $1115 \mathrm{z}$ and $1145 \mathrm{z}$ were actually moving in a slightly different direction rotated $40^{\circ}$ toward the north. This can likely be explained by the stronger curvature of the trailing wave fronts as seen in the SAR imagery [45].

At S4, the depression soliton from offshore was still visible as a broad, leading, thermocline depression from 1400 to $1430 \mathrm{~h}$. The horizontal velocity components were consistent with those 


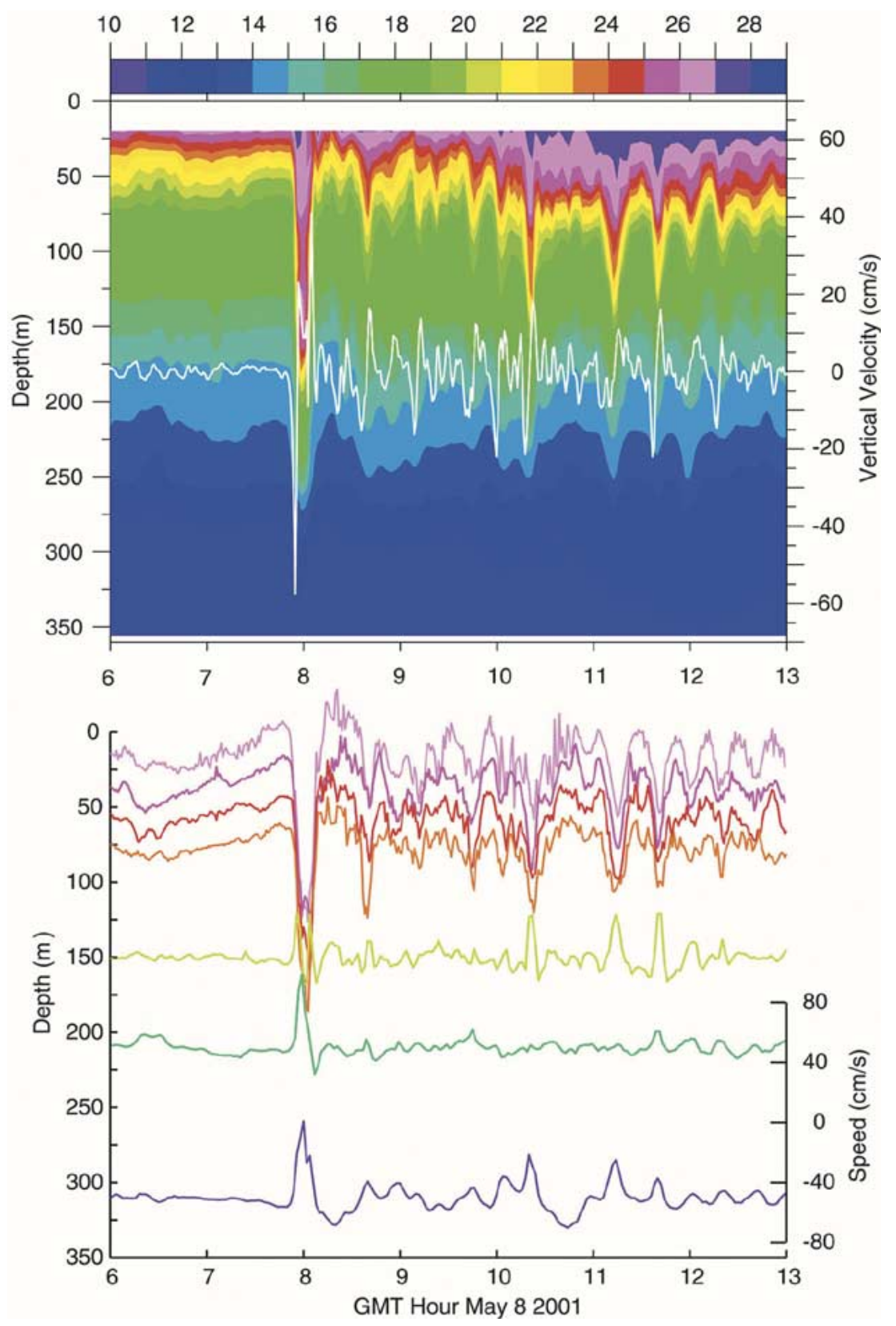

Fig. 11. (a) Temperature and vertical velocity (top panel), and u-component (bottom panel) for the May 8 soliton packet observed at ASIAEX mooring S7 on the $350 \mathrm{~m}$ isobath. The vertical velocity (white line, top) was sampled by the 90-m ADCP range cell, one of the closest bins to the transducer heads. The upper layer horizontal velocities are from the ADCP and the lower layer velocities are from the three Aanderaa current meters.

described above but this broad depression had no signature at all in the vertical velocity. This depression was likely created offshore of S4, or perhaps sub-observation scale turbulence occurring in this region smeared out the vertical velocity [4]. Trailing the downward pulse, a packet of seven elevation waves appeared [Fig. 11(b)]. These waves looked nearly uniform in amplitude but were rank-ordered in velocity. Each elevation soliton was preceded by a strong upward pulse of vertical velocity followed by a trailing downward pulse. The magnitudes were still quite strong, about $30 \mathrm{~cm} \mathrm{~s}^{-1}$ upward on the leading edge and $25 \mathrm{~cm}$ $\mathrm{s}^{-1}$ downward on the trailing edge. The horizontal velocities were order $50 \mathrm{~cm} \mathrm{~s}^{-1}$ offshelf in the upper layer and $35 \mathrm{~cm} \mathrm{~s}^{-1}$ onshelf in the lower layer. The nodal point can be better identified using the ADCP data at S4 than with the broadly spaced current meter data at S7 and occurred at around $66 \mathrm{~m}$ depth. The polarity of the waves was reversed with respect to the depression waves observed further offshore. This description of the orbital velocities for elevation waves is once again in excellent agreement with previous theoretical work [7].

\section{DISCUSSION}

\section{A. Soliton Generation vs. Luzon Strait Tides}

The temperature and pressure time series at Mooring S7 indicated an unusual relationship between the appearance of the waves and the fortnightly beat of the local barotropic tides (Fig. 3). It has now been demonstrated however that the largest waves were generated in the vicinity of the Batan 

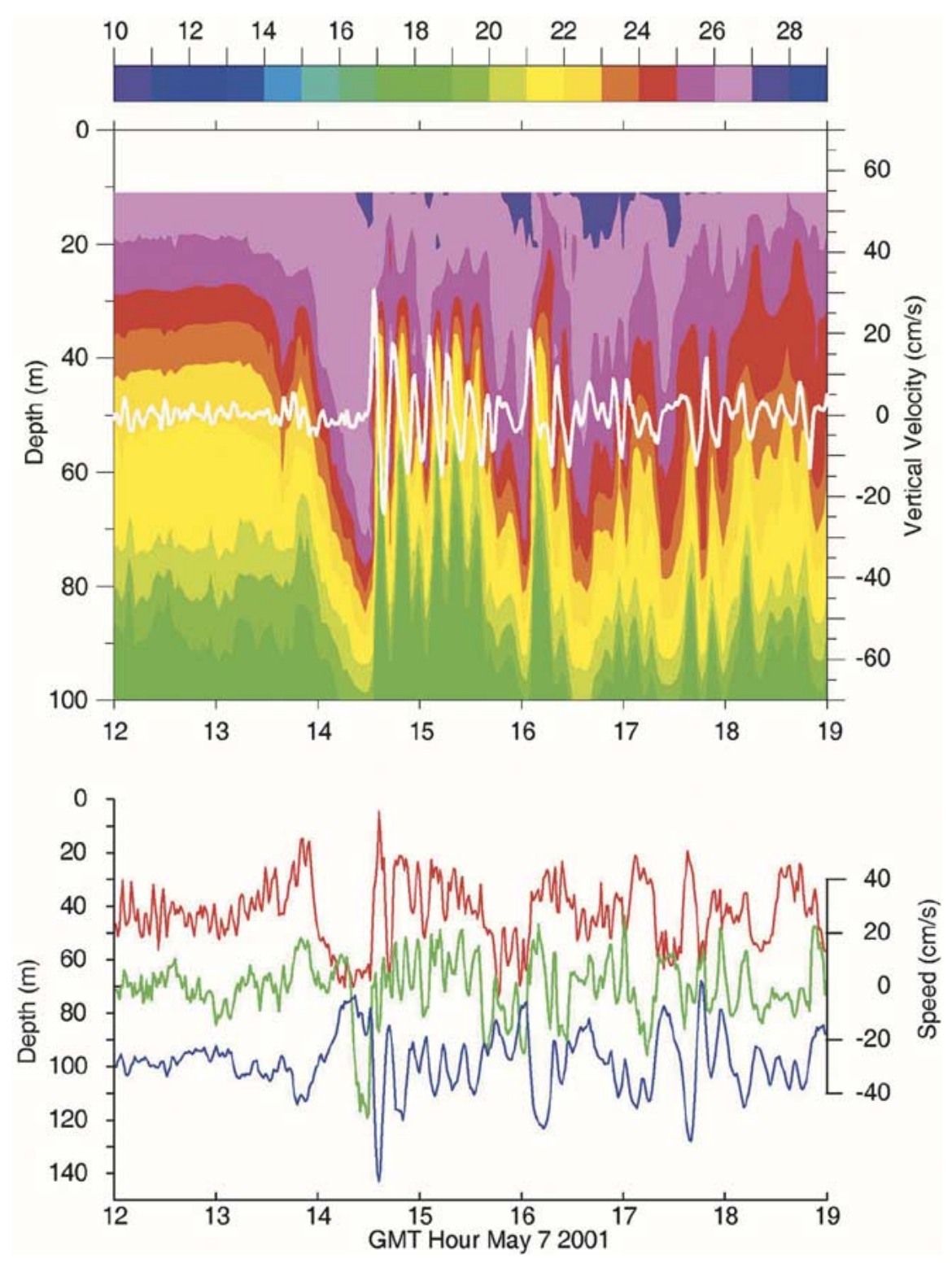

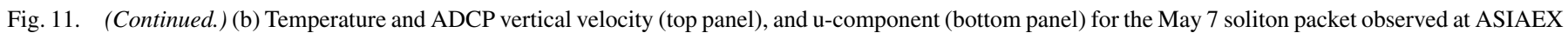

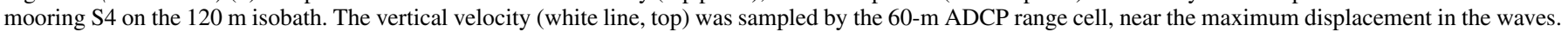
In the lower panel, the velocities are from $42 \mathrm{~m}$ (red), $70 \mathrm{~m}$ (green), and $98 \mathrm{~m}$ (blue) respectively.

Islands in the Luzon Strait, some $485 \mathrm{~km}$ away. Given the paths and estimated propagation speed $\left(1.5 \mathrm{~m} \mathrm{~s}^{-1}\right)$ presented above (Fig. 8, Table III) it would take the waves about $3.7 \mathrm{~d}$ to travel from the generation region to the observation point. Based on scatter in the phase speed observations and variation in the total path length traveled, the error in this calculation is around $0.25 \mathrm{~m} \mathrm{~s}^{-1}$, which translates to about a half a day over the distance traveled. Therefore, the relevant comparison is the phase relationship between the Luzon Strait tides and the time the waves arrived at the ASIAEX array lagged back by approximately $3.7 \pm 0.5$ days.

Since no in situ observations were made in the Luzon Strait as part of the ASIAEX program, the tides there were calculated using the global tidal model PCTides [47]. PCTides is an easily relocatable, 2-D (barotropic), depth integrated, constant density, data assimilative model which has been rigorously verified at several sites around the world. All the major data bases needed to run a simulation including DBDB5 topography are imbedded in the model. The tidal phases and heights on the open boundaries are taken from the Grenoble FES95.1.2 standard. The model computes the M2, S2, K2, N2, O1, K1, Q1, and $2 \mathrm{~N} 2$ tidal components. This is not a complete picture by any means, however these eight components contained 78 percent of the observed variance in the pressure gauge deployed at station S7 (Table II).

For this application, the boundaries of the region to be simulated $\left(15-26^{\circ} \mathrm{N}, 115-125^{\circ} \mathrm{E}\right)$ were chosen to be in open water well away from both the ASIAEX observations and the Luzon Strait. Other boundaries were tried and the model results were not sensitive to this. There were 54 tidal stations within this region which were included in the simulation, i.e., the model was well constrained. As a check, the tidal heights were first computed at mooring S7 for comparison with the moored pressure gauge there and the agreement was excellent [Fig. 12 (bottom)]. 


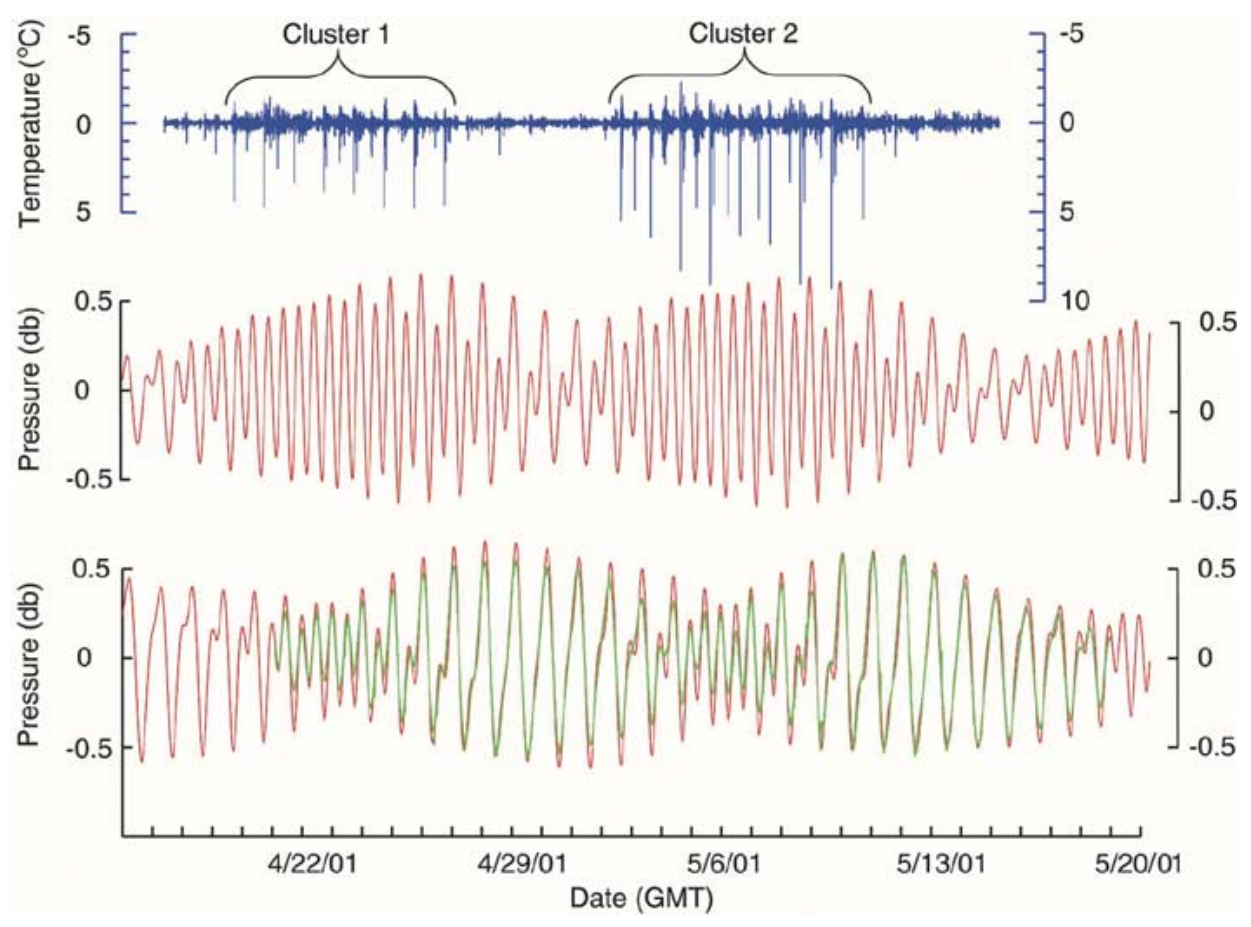

Fig. 12. Bottom: Observed (green line) and PCTides-generated (red line) barotropic tidal amplitudes at ASIAEX site S7 on the Chinese continental slope. Middle: The barotropic tidal height at Batan Island in the Luzon Strait, as computed by the global tidal model PCTides. Top: The high-pass filtered temperature fluctuations at $140 \mathrm{~m}$ (blue line) at ASIAEX site S7 on the $350 \mathrm{~m}$ isobath, phase-shifted 3.7 days to the left (earlier) to account for the propagation time between the proposed generation site (the Luzon Strait) and the mooring.

The model overestimated the tidal heights with an rms difference of $15 \mathrm{~cm}$, but the mixed diurnal-dominant nature of the tide and the fortnightly beat were accurately reproduced. As a further check, the PCTides output for $20^{\circ} 20^{\prime} \mathrm{N}, 121^{\circ} 54^{\prime} \mathrm{E}$ (between Batan and Sabtang Islands) was compared against the Oregon State University (OSU) TOPEX/Poseidon crossover global inverse solution TPXO.3 [48] for the same location. TPXO.3 is a different global model of ocean tides, which best-fits, in a least-squares sense, the Laplace Tidal Equations and crossover data from the first 40 TOPEX/Poseidon orbit cycles. The inputs and methodology are quite different from the PCTides model, however the two models produced virtually identical results for the locations studied in the northeastern SCS and Luzon Straits. These model/data and model/model comparisons provide reasonable confidence that the model-generated tidal heights in the Luzon Straits are correct.

The simulated tides between the Batan and Sabtang Islands in the Luzon Strait [Fig. 12 (middle)] were very different from the Chinese continental shelf. The Luzon tides remained semidiurnal even at spring tide, and the fortnightly beat was shifted earlier by 3.5 days. This resulted from a net phase shift between the diurnal and semidiurnal tidal components of about $35^{\circ}$ between the Luzon Strait and Chinese continental shelf. When the solitons, as indicated by the temperature fluctuations at S7 lagged back 3.7 days to allow for propagation, are plotted together with the PCTides-simulated Batan Island tides (Fig. 12), several interesting relationships become apparent. Given the error in the calculation, one cannot attribute individual waves to individual tidal peaks, but one can say: a) The solitons were generated around the time of the spring tide and not during the neap tide, in agreement with many other locations around the world
[26]. b) The a-waves were generated on the higher-high tides and the b-waves on the lower high tides, which explains why the a-waves were both larger and more nonlinear. c) The amplitude of the a- and b-waves was most equal near the center of the clusters when the diurnal inequality at the generation site was minimal.

Armed with this new information from the global tidal models, we return to the issue of why the a-waves arrived daily at 0800 with such astounding regularity, while the $\mathrm{b}$ waves arrived about an hour later each day (Fig. 4). The cluster 1 waves (not shown) displayed similar behavior, but the cluster 1 a-waves arrived at around 1000 rather than 0800 . There are two plausible explanations for this. The first is that the a-waves were phase-locked predominantly to the diurnal (K1) tide while the b-waves were associated with the M2 tide on the weaker of the two daily oscillations. With a period of 23 hours and 56 minutes, the $\mathrm{K} 1$ tide arrives at about the same time daily and the 4-minute changes would not be discernable within each cluster of waves, given all the other variability along the propagation path. Between the two clusters, the cluster 2 waves would arrive about an hour earlier than the cluster 1 waves a fortnight earlier. This shift has the correct sign but is not an exact match for the 2-h difference observed. The b-waves would arrive 50 min later each day as is usual for the M2 tide whose period is $12.42 \mathrm{~h}$. This unusual tidal structure should be observable at the generation site but was not present in the output from the global tidal models (Fig. 12). It would likely result from local topographic interactions and it is not obvious that this could be reproduced by a global tidal model. This explanation remains just a hypothesis which could benefit from additional in situ observations at the generation site. 
The second possibility is that both wave types advanced $50 \mathrm{~min} /$ day, but the lead soliton continued to arrive at about the same hour of the day during May 6-9 because its phase speed was increasing along with its amplitude and nonlinearity. Restated, the lead soliton out-ran the pack by a little more each day by an amount proportional to its increasing amplitude. This would also manifest itself as increased dispersion, with increasing elapsed time between the arrival of the first two peaks in each packet. This was in fact observed during May 5-9 (Fig. 4, Table III) but on May 10-11, the wave amplitude decreased by $60 \mathrm{~m}$ and the lead soliton did not fall behind, still arriving at 0800 daily. A more quantitative analysis also proved inconsistent with this explanation. To travel the $485 \mathrm{~km}$ distance between Luzon and S7 one hour faster each day requires only a $2-\mathrm{cm} \mathrm{s}^{-1}$ speed increase with respect to the day before. The lead soliton increased in amplitude by about $20 \mathrm{~m}$ per day during the May 5-9 time period. Under the fully stratified deep water EKdV theory, an amplitude increase of $20 \mathrm{~m}$ in open water provides an increase of order $19 \mathrm{~cm} \mathrm{~s}^{-1}$ in the nonlinear phase speed, which would cause the waves to arrive 10 hours earlier each day. Clearly this was not observed, and in fact very little correlation was observed between wave amplitude and phase velocity at all (Fig. 7, Table III). Given these results, the more likely explanation seems to be that the wave arrivals were somehow linked to the diurnal (a-waves) and semidiurnal (b-waves) tides in the generation region, although the physical mechanism for this is not clear. Some direct current observations from the Luzon Ridge in the vicinity of the Batan Islands would be useful in sorting this out.

\section{B. Wave Amplitudes in Cluster 1 Versus Cluster 2}

One of the most obvious and robust features of the data set (Fig. 3, Table III) is that the amplitude of the cluster 2 waves was much greater than the cluster 1 waves, in both displacement and velocity, by any measure you might choose. Why should this be? The strength of the waves arriving at S7 depends on both the conditions at the generation site and conditions encountered along the route as the waves propagated $485 \mathrm{~km}$ across the northeastern South China Sea. Considering first wave generation, the initial strength of the waves depends on the total flow across the sill and the local stratification at the sill. Both these parameters depend not only on the tides, but also the mesoscale variability, in this case the position of the Kuroshio intrusions into the Luzon Strait. According to the global tidal models (Fig. 12) the Luzon Strait barotropic tide varied little between the two wave clusters, so the state of the Kuroshio inflow was the more likely cause of the amplitude variability between clusters.

As reviewed in the introduction, the Kuroshio sometimes swings through the SCS and sometimes not. The main current sometimes passes over the shallow portion of the Luzon Ridge (which includes the Batan Islands), and sometimes loops around it, entering and exiting the sea via deeper water to the south and north of the islands. Assuming the wave generation mechanism is similar to other locations such as the Sulu Sea, the Straits of Gibralter, and Massachusetts Bay, the initial hydraulic jump which generates the waves forms on the ebb (southeastward) tide. The waves are then released on the flood (northwestward)

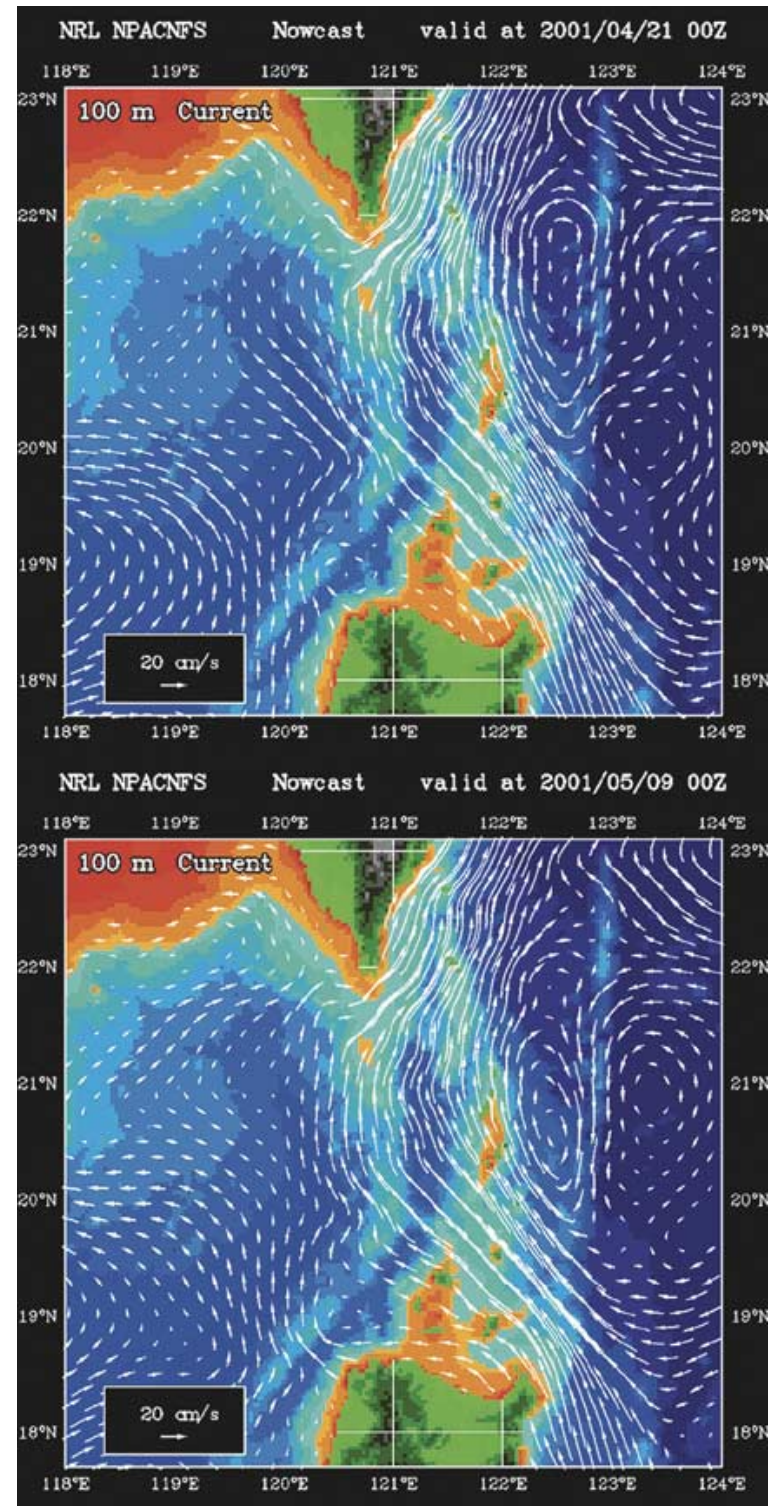

Fig. 13. Bottom topography (colors) and current vectors at $100 \mathrm{~m}$ depth (white arrows) as computed by the NRL North Pacific Nowcast/Forecast system (NPACNFS) showing the difference in the flow through the Batan Islands on April 21 (top, internal wave cluster 1) versus May 11 (bottom, internal wave cluster 2). The ASIAEX internal waves are presumed generated around the island group centered near $20^{\circ} 20^{\prime} \mathrm{N}, 122^{\circ} 00^{\prime} \mathrm{E}$ in the Luzon Strait. The stronger NW flow on April 21 weakens the total flow across the sills at ebb tide, causing weaker solitons to be generated. (Figure courtesy of Dr. Dong-Shan Ko, Naval Research Laboratory).

tide and propagate WNW across the sea. Under this scenario, Kuroshio positions that enhance the ebb tide would contribute to stronger internal bores and subsequently, solitons while Kuroshio flows that oppose the ebb tide would lead to weaker solitons.

Lacking in situ observations in the Luzon Strait, the position of the Kuroshio can be estimated instead using the output from the NRL North Pacific Nowcast/Forecast System (NPACNFS). The currents at $100 \mathrm{~m}$ were compared for the April 21, 2001 (cluster 1) and May 11, 2001 (cluster 2) time frames (Fig. 13). During this time, the model indicates that the Kuroshio was in the process of intruding further westward into the South China Sea. On April 21, there was a slight intrusion leading to a strong 
NW flow through the Batan Islands in direct opposition to the ebb tide. By May 11, the current looped around the islands, inward (NW) to the south and outward (NE) to the north with relatively weak flow near the Islands themselves. These Kuroshio positions are consistent with weaker solitons being generated during April 23-30 than during May 6-14, 2001 via the released standing-wave mechanism.

What about the effects of advection on wave propagation across the sea? In this case, a stronger, larger loop current through the northeastern SCS would seem advantageous, reducing the travel time for the waves across the sea to the Chinese continental shelf. The shear in the water column along the propagation path could also reduce or enhance the wave amplitude and speed, but more detailed observations and calculations would be necessary to determine the effect. During April 2000, there was a much larger Kuroshio intrusion than during April 2001 [3]. The solitons observed at IW1 during 2000 were also larger than the solitons observed nearby at S7 during 2001 [49]. So, there is some incidental evidence to support the idea that more energetic Kuroshio intrusions that loop around the Luzon Ridge favor the generation of larger amplitude internal waves. The total effect of the Kuroshio intrusions on wave generation and propagation is not obvious and is a topic requiring further investigation. A full year's measurements in both the generation region and on the Chinese continental shelf are needed to study this phenomenon and determine its predictability.

\section{Impacts of Tropical Storm Cimaron on Cross-Basin Propagation}

Another interesting aspect of Fig. 4 is that the wave packets on May 13 and 14 arrived later in the day than the rest of the a-waves, despite being similar in amplitude (Table III). The lead solitons on May 6 to 12 arrived at about $0800 \mathrm{z}$, while the May 13 wave was delayed 55 min to 0855 and the May 14 wave an additional 95 min 1030. These represent very small differences in propagation speed over $485 \mathrm{~km}$ : The waves traveled just 2.0 and $4.5 \mathrm{~cm} \mathrm{~s}^{-1}$ slower respectively than their earlier counterparts as they crossed the sea. The passage of tropical storm Cimaron through the NE South China Sea at this time seems beyond coincidence. At $0000 \mathrm{z}$ on May 12, the storm was centered directly in the path of the internal waves with winds of $25 \mathrm{~m} \mathrm{~s}^{-1}$ gusting to $32 \mathrm{~m} \mathrm{~s}^{-1}$.

A simple feasibility study was conducted to see if tropical storm Cimaron could slow down the waves by a few $\mathrm{cm} \mathrm{s}^{-1}$. For this exercise, the two-layer, weakly nonlinear, infinite depth equations were used to calculate the phase speed over the SCS deep basin [50], [51]. The equation for the phase speed is

$$
c=\sqrt{\frac{g\left(\rho_{2}-\rho_{1}\right) h_{1}}{\rho_{1}}}
$$

where all the parameters are standard or previously defined. Using a conglomeration of all available deep CTD data, the prestorm conditions were $\rho_{1}=1023 \mathrm{~kg} \mathrm{~m}^{-3}, \rho_{2}=1026$ $\mathrm{kg} \mathrm{m}^{-3}, \mathrm{~h}_{1}=60 \mathrm{~m}$, and $\mathrm{g}=9.8 \mathrm{~m} \mathrm{~s}^{-2}$ which results in a phase speed in deep water of $1.31 \mathrm{~m} \mathrm{~s}^{-1}$. If the storm deepened the surface mixed layer to $70 \mathrm{~m}$ and increased the upper layer density by $0.5 \mathrm{~kg} \mathrm{~m}^{-3}$, leaving the infinitely deep lower layer unchanged, the new phase speed would be slightly slower at $1.29 \mathrm{~cm} \mathrm{~s}^{-1}$. This result is somewhat speculative but suggests that mixing by the tropical storm in the central SCS could slow down the internal waves enough to account for the arrivals observed on May 13 and 14 (Fig. 4). The results are quite sensitive to the choice of parameters however and should be viewed with caution.

\section{Comparison With Other Locations}

A rigorous comparison of solitons worldwide is not our purpose in this manuscript, however comparison with a few other sites is useful and provides some context for these observations. The previously observed solitons which are most similar to the SCS solitons in terms of their latitude and basin configuration are the Sulu Sea solitons [26], [35]. The Sulu Sea solitons are generated by flow over a shallow sill (200 m depth) between Pearl Bank and Doc Can Island separating the Sulu and Celebes Seas. The waves propagated NNW and were observed in deep water $(>1500 \mathrm{~m})$ at distances of 100 and $220 \mathrm{~km}$ away from the sill. The experiment also obtained observations in the lee of the sill in the generation region. The entire sea is about $385 \mathrm{~km}$ across (to Palawan Island) and is located to the south of the SCS between $6-9^{\circ} \mathrm{N}$

The tides at the sill in the Sulu Sea were mixed with a diurnal inequality and fortnightly beat. Like the SCS, the solitons were generated only around the spring tide and were stronger on the high side of the diurnal inequality. This indicates that the flow was always supercritical across the sill around the time of the spring tide irrespective of the mesoscale flow, which could enhance or reduce the strength of the waves but not eliminate them entirely. There was much variability between packets with no two being the same. A quantitative summary of the SCS waves vs. the Sulu Sea waves can be had by comparing our Table III with Table I in [26]. The amplitude of the Sulu Sea waves, calculated according to our (1) ranged from 10 to $90 \mathrm{~m}$ versus 29 to $142 \mathrm{~m}$ for the SCS waves. The near surface currents are consistent with this, being approximately $1 / 3$ stronger in the SCS at 150 versus $110 \mathrm{~cm} \mathrm{~s}^{-1}$ for the SCS and Sulu Sea, respectively. The SCS waves were much narrower than the Sulu Sea waves, as defined by their half amplitude width. The Sulu Sea waves had half-amplitude widths ranging from 2000-3000 m, whereas the SCS waves had half-amplitude widths of only 380-950 m. This is consistent with both the KdV and EKdV theories which call for an inverse relationship between wave amplitude and half-amplitude widths. The much larger SCS waves would be expected to be narrower also and this was born out by the observations. The Sulu Sea waves should also be wider since they were observed in deeper $(\sim 3000 \mathrm{~m})$ water and had not yet begun to shoal.

The phase speed of the waves was quite interesting since the Sulu Sea waves traveled faster ( 1.8 to $\left.2.6 \mathrm{~m} \mathrm{~s}^{-1}\right)$ than the SCS waves ( 0.83 to $\left.1.68 \mathrm{~cm} \mathrm{~s}^{-1}\right)$ despite having smaller amplitudes. This is because the nonlinear phase speed depends only weakly on wave amplitude and more strongly on stratification and layer depth (or mode structure), which favors the Sulu Sea waves.

There were also a number of important differences in the packet structure of the SCS waves versus the Sulu Sea waves. All the Sulu Sea waves resembled the SCS type-a waves with 
approximately rank ordered structure in 3-10 waves per packet, with 3-4 the most common number. There were no type-b waves observed in the Sulu Sea. These waves, consisting of a single large soliton growing out of the middle of the packet, generated on the weak side of the diurnal inequality, have not been reported elsewhere in the literature and may be unique to the SCS situation. The dynamics of these b-waves is poorly understood. The elapsed time between the first and second peaks was much longer (50-180 min) for the SCS a-waves than the Sulu Sea waves (35-55 min). The largest cluster 2 type-a waves in the SCS ranged from 88-142 min. These times, which are what a mooring actually observes, are consistent with greater dispersion in the SCS waves which have traveled almost twice as far to the observation point than the Sulu Sea waves (450 versus $220 \mathrm{~km}$ ). However, since slower phase speeds were used in the SCS to convert the periods to wavelengths, the wavelengths in the two seas came out to be about the same, $5-16 \mathrm{~km}$ for the Sulu Sea and 4.8-13.6 km for the SCS.

The Sulu Sea authors also used SAR imagery to observe the wavelengths directly. This was also done for the SCS [45] but fewer images were available and only the May 5, 9, and 18 waves were captured. The May 5 and 18 dates were benign times for the solitons and only small waves were present, even though the May 5 wave packet looks large in the RADARSAT imagery. On May 9, the a-wave packet that arrived at mooring S7 at 0800 May 10 is clearly seen, and the distance between the two brightest lines in the SAR image ranged from 14 to $26 \mathrm{~km}$ along the crest of the waves [45], Figs. 2 and 5. The distance calculated from the moorings was $13.6 \mathrm{~km}$, at the low end of this range. While reasonable, these comparisons illustrates the difficulty of using the surface information to infer the in situ properties of the waves. The brightness of the lines on the SAR image depends on a variety of air/sea interaction processes, and the strongest reflections in an image are not necessarily the strongest signals in situ.

The SAR imagery from the Yellow and East China Sea indicates that internal solitons are prevalent there also [52] but there is little in the way of in situ observations. Some moorings and thermistor chains were deployed in the ECS recently during the ASIAEX ECS program during 2000 and 2001. These observations were made in the central ECS in a region bounded by $28^{\circ}$ to $30^{\circ} \mathrm{N}, 126^{\circ} 30^{\prime}$ to $128^{\circ} \mathrm{E}$ which included a flat section of the continental shelf in the NW corner (95-150 m deep), the shelf break running diagonally across the middle from SW to NE, and a portion of the slope and deep basin (>2000 m deep) in the SE quadrant. Only one soliton event was observed during April 2000 and none during May-June 2001, although an energetic internal tide and ordinary high-frequency internal waves were observed during 2001 [46]. Soliton generation was the exception rather than the rule at this location and required some rather special conditions for the shelf-edge flow to become supercritical. A soliton packet was only generated during an offshore migration of the Kuroshio over the shelf break at the time of the off-shelf (ebb) tide. The ECS solitons were smaller $(40 \mathrm{~m}$ amplitude, 500-800 $\mathrm{m}$ wavelength), had weaker currents $(70 \mathrm{~cm}$ $\mathrm{s}^{-1}$ ), and were much less dispersed (period $=15$ minutes) than the SCS waves, indicating they were generated close by at the continental shelf break rather than at some distant sill. Thus, the solitons in the central ECS were much more like the internal waves over the New England continental shelf (see below) than the waves in the South China Sea or the Sulu Sea.

The waves over the New England shelf, e.g., [23], [24] are similar to the ECS shelf break waves but even smaller and weaker. Soliton amplitudes were order $10 \mathrm{~m}$ in $70 \mathrm{~m}$ depth in the SWARM region [23] and 15-30 in the Shelfbreak PRIMER experiment [24]. Typical periods in both experiments were order $15 \mathrm{~min}$ or less indicating local generation processes. Wave generation was intermittent and seemingly related to the mesoscale circulation in both experiments, as generated by a storm in SWARM and the meandering of the shelf break jet in PRIMER. There are indications in the SCS data from depths less than $90 \mathrm{~m}$ that locally generated waves like those of the New England shelf may exist north of mooring S4.

The picture which is emerging from these observations is that solitons which were generated remotely at a sill or island chain and have propagated large distances across deep water are more energetic than waves generated locally at a shelf break. The pumping of water across these sills in the Sulu Sea and Luzon Strait (as well as the Straits of Gibralter and the Great Channel in the Andaman Sea) provide a more reliable and predictable generating mechanism than the shelf break flow. Interactions between the tidal flow and the mesoscale flow in the generating region are observable in many of the locations which have been studied so far. The mesoscale flow modulates the strength of the waves generated near sills but may suppress them entirely or cause anomalous generation near continental shelf breaks.

\section{Summary AND CONCLUSION}

A combination of moored and shipboard observations were made near the continental shelf break in the South China Sea between the southern tip of Taiwan and Dongsha Island as part of the Asian Seas International Acoustics Experiment (ASIAEX). The moored array, which is the focus of this paper, consisted of eight densely-instrumented oceanographic moorings with seven deployed in an across-shelf line spanning 800 to $72 \mathrm{~m}$ depth and the eighth moored alongshore on the $80 \mathrm{~m}$ isobath. The moorings sampled velocity, temperature and conductivity at intervals sufficient to resolve the high frequency internal wave field as well as the tidal and mesoscale motions. The moorings were in the water for 28 days during 21 April-19 May 2001.

The most energetic motions by far turned out to be the highly nonlinear internal soliton packets propagating through the array. The largest waves can be clearly identified as trans-basin waves which were generated in the Luzon Strait and propagated about $485 \mathrm{~km}$ toward the WNW before encountering the most offshore mooring. Inverse ray tracing identified the most likely sources as over the Luzon Ridge near the Batan Islands, in agreement with earlier work. Unfortunately no in-situ observations were made near the islands, but comparison with two independent global tidal models indicates that the waves were generated around the time of the spring tide in the straits, in agreement with other sites around the world.

The trans-basin depression waves arrived at the offshore mooring in two clusters lasting 7-8 days each separated by five days when no waves were observed. The waves in the later cluster had much greater amplitude than the waves in the earlier cluster. Within each cluster, two types of waves arrived 
which have been named type-a and type-b. The type-a waves had greater amplitude than the type-b waves and arrived with remarkable regularity at the same time each day, $24 \mathrm{~h}$ apart. These waves resembled other soliton packets reported in the literature, with the largest soliton leading and an approximately rank-ordered structure behind. The type-b waves were weaker than the type-a waves, arrived an hour later each day, and generally consisted of a single soliton growing out of the center of the wave packet. The type-b waves do not resemble waves observed at other sites and represent some new generation and propagation process. Both types of wave arrivals were associated with a tidal bore. The initial tidal bore associated with the a-waves was larger than the one associated with the b-waves. The amount of energy in the tidal bore/internal waves decreased/increased each day as the solitons strengthened from May 6-9. Given the strong diurnal inequality evident in the modeled barotropic tides for the generation region, the type-a waves were apparently generated on the strong side of the diurnal inequality while the type-b waves were generated on the weaker beat. The timing of the wave arrivals is consistent with the type-a waves being generated primarily by the nonprogressing $\mathrm{K} 1$ tide while the type-b waves were generated by the M2 tidal constituent.

As the waves traveled up the continental slope from 350 to $200 \mathrm{~m}$ depth, the huge lead solitons began feeling the bottom. These waves were forced up and out by the bottom, creating reduced amplitude and greater half-amplitude width. Some the largest solitons split into two lead solitons. Starting around May 10 , the local spring tide, a second tidal bore appeared which was diurnal, out of phase with the offshore bore, and presumed to be locally generated. The new bore interacted with the incoming solitons, smearing them out during the May 10-13 time frame. All the solitons remained depression waves at the $200 \mathrm{~m}$ isobath.

The wave field was radically transformed by the time it reached the $120 \mathrm{~m}$ isobath. What had initially been the large-amplitude lead soliton (or solitons) now formed a broad region of thermocline depression, and elevation waves sprang up behind it. The local tidal bore also depressed the thermocline all the way to the bottom for twelve hours at a time, and elevation waves grew out of this region also. Some depression waves still existed during the other phase of the internal tide when the thermocline was high. The relatively simple idea of a critical point (upper and lower layer depths equal) at some isobath as the bottom shoals under a relatively constant-depth thermocline was inadequate to describe the wave field. The critical point was a dynamic, rather than a static location, and changed its position often in response to the passage of the tidal bore and even the internal waves themselves.

The modal structure of the waves, both depression waves and elevation waves, showed remarkable agreement with the theory. Offshore, the depression waves were almost all mode- 1 waves, with strong orbital velocities in the direction of wave propagation in the upper layer and toward the opposite direction in the lower layer. The nodal point statistically occurred around $140 \mathrm{~m}$ but was not well resolved by the spacing of the deeper current meters. The ADCP observed vertical velocities (w) as large at $60 \mathrm{~cm} \mathrm{~s}^{-1}$ in the largest soliton. Large downward vertical velocity preceded the arrival of each thermocline depression, and large upward $\mathrm{w}$ followed along behind. The wave polarity reversed in the elevation waves with a nodal point near $66 \mathrm{~m}$ over the $120 \mathrm{~m}$ isobath. There was upward flow ahead of the wave, onshore (upslope) flow along the bottom, and downward vertical velocity behind the wave. The elevation waves were less dispersed than the trans-basin waves, due to their local generation.

Model results suggest that mesoscale flows driven by Kuroshio intrusions in the Luzon Strait and tropical storm Cimaron modulated the generation and propagation of the internal waves. Strong Kuroshio currents toward the northwest would theoretically weaken the soliton generation mechanism around the Batan Islands by causing weaker total flow across the sills at ebb tide compared to if these currents were absent or in the opposite direction. The NRL North Pacific Nowcast/Forecast System showed such a flow was present at the time the cluster 1 waves were generated, possibly accounting for these waves being much weaker than the cluster 2 waves generated a fortnight later. The wave arrivals on May 13 and 14 were delayed 1.0 and 2.5 hours respectively relative to the rest of the cluster 2-a waves on May 6-12. This corresponds to the time when tropical storm Cimaron was directly between the wave generation site and the observation point. A simple calculation suggests that mixed layer deepening beneath the storm could retard the wave arrivals by a similar amount.

The fascinating ASIAEX data set has thus illuminated many new results where the propagation and shoaling of very large amplitude internal solitons is concerned, but posed many new questions as well. Lacking data from the other 11 months of the year, we can only guess what the seasonality of the solitons might be. Our hypotheses regarding generation are also based entirely on numerical models rather than in-situ observations. A full year's observations in both the generation and shoaling region are needed to move toward the goal of predicting soliton occurrence and their energy levels in the northeastern South China Sea. Additional observations in shallow water are also needed, to better understand the elevation waves and the ultimate fate of the energy they carry.

\section{ACKNOWLEDGMENT}

The work at sea was conducted from the Taiwanese research vessels Ocean Researcher I, Ocean Researcher 3, and Fisheries Researcher 1 . The skill and enthusiasm of the officers and crew of all these vessels is gratefully acknowledged. The authors would like thank the technical support groups of the Woods Hole Oceanographic Institution, the Naval Postgraduate School, and the National Taiwan University, who all worked tirelessly to execute the field work at sea.

\section{REFERENCES}

[1] C.-S. Chiu, S. R. Ramp, C. W. Miller, J. F. Lynch, T. F. Duda, and T.-Y. Tang, "Acoustic intensity fluctuations induced by South China Sea internal tides and solitons," IEEE J. Ocean. Eng., vol. 29, pp. 1249-1263, Oct. 2004.

[2] T. F. Duda, J. F. Lynch, J. D. Irish, R. C. Beardsley, S. R. Ramp, C.-S. Chiu, T.-Y. Tang, and Y.-J. Yang, "Internal tide and nonlinear internal wave behavior at the continental slope in the northern South China Sea," IEEE J. Ocean. Eng., vol. 29, pp. 1105-1130, Oct. 2004.

[3] G. Gawarkiewicz, J. Wang, M. Caruso, S. R. Ramp, K. Brink, and F. Bahr, "Shelfbreak circulation and thermohaline structure in the northern South China Sea: Contrasting spring conditions in 2000 and 2001," IEEE J. Ocean. Eng., vol. 29, pp. 1131-1143, Oct. 2004.

[4] M. H. Orr and P. C. Mignerey, "Nonlinear internal waves in the South China Sea: Observation of the conversion of depression internal waves to elevation internal waves," J. Geophys. Res, vol. 108, no. 3 064, 2003. 
[5] C. C. Ebbesmeyer, C. A. Coomes, R. C. Hamilton, K. A. Kurrus, T. C. Sullivan, B. L. Salem, R. D. Romea, and R. J. Bauer, "New observations on internal waves (solitons) in the South China Sea using an acoustic doppler current profiler,' in Proc. Marine Technology Society, New Orleans, LA, 1991, pp. 165-175.

[6] J. B. Bole, C. C. Ebbesmeyer, and R. D. Romea, "Soliton currents in the South China Sea: Measurements and theoretical modeling," in Proc. 26th Annual Offshore Technology Conference (OTC), Houston, TX, USA, 1994, pp. 367-376.

[7] M.-K. Hsu and A. K. Liu, "Nonlinear internal waves in the South China Sea," Canadian J. Remote Sensing, vol. 26, pp. 72-81, 2000.

[8] J. Wang and C.-S. Chern, "On the Kuroshio branch in the Taiwan strait during wintertime," in Prog. Oceanogr., vol. 21, 1988, pp. 469-491.

[9] S. Hellerman and M. Rosenstein, "Normal monthly wind stress over the world ocean with error estimates," J. Phys. Oceanogr., vol. 13, pp. 1093-1104, 1983.

[10] E. J. Metzger and H. E. Hurlburt, "Coupled dynamics of the South China Sea, the Sulu Sea, and the Pacific Ocean," J. Geophys. Res., vol. 10, pp. 12331-12 352, 1996

[11] P.-T. Shaw, "The intrusion of water masses into the sea southwest of Taiwan," J. Geophys. Res., vol. 94, pp. 18 213-18 226, 1989.

[12] T. Hatayama, T. Awaji, and K. Akitomo, "Tidal currents in the Indonesian Seas and their effect on transport and mixing," J. Geophys. Res., vol. 101, pp. 12 353-12 373, 1996.

[13] P. Mazzega and M. Berge, "Ocean tides in the Asian semi-enclosed seas from TOPEX/POSEIDON,” J. Geophys. Res., vol. 99, pp. 24 867-24 $881,1994$.

[14] A. L. Ye and I. S. Robinson, "Tidal dynamics in the South China Sea," Geophys. J. R. Astron. Soc., vol. 72, pp. 691-707, 1983.

[15] A. K. Liu, Y. S. Chang, M.-K. Hsu, and N. K. Liang, "Evolution of nonlinear internal waves in the East and South China Seas," J. Geophys. Res., vol. 103, pp. 7995-8008, 1998.

[16] Y.-J. Yang, W. D. Liang, T. Y. Tang, M.-K. Hsu, A. K. Liu, and M. H. Chang, "ASIAEX 2000 South China Sea Mooring Data Report,", vol. 72, National Taiwan University Technical Report, 2001.

[17] L. Armi and D. M. Farmer, "The flow of mediterranean water through the strait of Gibraltar,' Progr. Oceanogr., vol. 21, pp. 1-105, 1988.

[18] D. M. Farmer and L. Armi, "The flow of Atlantic water through the strait of Gibraltar," Progr. Oceanogr., vol. 21, pp. 1-105, 1988.

[19] _ "The generation and trapping of solitary waves over topography," Science, vol. 283, pp. 188-190, 1999.

[20] D. M. Farmer and J. D. Smith, "Tidal interaction of stratified flow with a sill in knight inlet," Deep-Sea Res., vol. 27 A, pp. 239-254, 1980.

[21] R. F. Gasparovic, J. R. Apel, and E. S. Kasischke, "An overview of the SAR internal wave signature experiment," J. Geophys. Res., vol. 93, pp. 12304-12316, 1988.

[22] A. K. Liu, "Analysis of nonlinear internal waves in the New York bight," J. Geophys. Res., vol. 93, pp. 12 317-12 329, 1988.

[23] J. R. Apel, M. Badiey, C. S. Chiu, S. Finette, R. Headrick, J. Kemp, J. R. Lynch, A. Newhall, M. H. Orr, B. H. Pasewark, D. Tielbuerger, K. von der Heydt, and S. Wolf, "An overview of the 1995 SWARM shallow-water internal wave acoustic scattering experiment," IEEE J. Ocean. Eng., vol. 22, pp. 465-500, 1997.

[24] J. A. Colosi, J. F. Lynch, R. C. Beardsley, G. Gawarkiewicz, A. Scotti, and C.-S. Chiu, "Observations of nonlinear internal waves on the New England continental shelf during the summer shelfbreak primer study," J. Geophys. Res., vol. 106, pp. 9587-9601, 2001.

[25] T. Maxworthy, "A note on the internal solitary waves produced by tidal flow over a three-dimensional ridge," J. Geophys. Res., vol. 84, pp. 338-346, 1979

[26] J. R. Apel, J. R. Holbrook, J. Tsai, and A. K. Liu, "The Sulu Sea internal soliton experiment," J. Phys. Oceanogr., vol. 15, pp. 1625-1651, 1985.

[27] A. Scotti and R. C. Beardsley, Large internal waves in Massachusetts bay. Part 1: Modeling generation, propagation, and shoaling, in J. Geophys. Res.. submitted for publication.

[28] A. R. Osborne and T. L. Burch, "Internal solitons in the Andaman Sea,' Science, vol. 208, pp. 451-460, 1980.

[29] L. A. Ostrovsky and Y. A. Stepanyants, "Do internal solitons exist in the ocean?," Rev. Geophys., vol. 27, pp. 293-310, 1989

[30] J. Small, Z. Hallock, G. Pavey, and J. C. Scott, "Observations of large amplitude internal waves at the Malin Shelf edge during SESAME 1995," Cont. Shelf Res., vol. 19, pp. 1389-1436, 1999.

[31] W. Choi and R. Camassa, "Fully nonlinear internal waves in a two-fluid system," J. Fluid Mech, vol. 396, pp. 1-36, 1999.

[32] J. Small, "A nonlinear model of the shoaling and refraction of interfacial solitary waves in the ocean. Part I: Development of the model and investigations of the shoaling effect," J. Phys. Oceanogr., vol. 31, pp. 3163-3183, 2001.
[33] J. R. Apel, "A new analytical model for internal solitons in the ocean," J. Phys. Oceanogr., submitted for publication.

[34] P. Holloway, E. Pelinovsky, and T. Talipova, "A generalized Korteweg-de Vries model of internal tide transformation in the coastal zone," J. Geophys. Res., vol. 104, pp. 18333-18350, 1999.

[35] A. K. Liu, J. R. Holbrook, and J. R. Apel, "Nonlinear internal wave evolution in the Sulu Sea," J. Phys. Oceanogr., vol. 15, pp. 1613-1624, 1985.

[36] J. Small, "A nonlinear model of the shoaling and refraction of interfacial solitary waves in the ocean. Part II: Oblique refraction across a continental slope and propagation over a seamount," J. Phys. Oceanogr., vol. 31, pp. 3184-3199, 2001.

[37] V. Vlasenko and K. Hutter, "Numerical experiments on the breaking of solitary internal waves over a slope-shelf topography," J. Phys. Oceanogr., vol. 32, pp. 1779-1793, 2002

[38] R. J. Joseph, "Solitary waves in a finite depth fluid," J. Phys. A: Math. Gen., vol. 10, pp. L225-L227, 1977.

[39] T. Kuboda, D. R. S. Ko, and L. Dobbs, "Propagation of weakly nonlinear internal waves in a stratified fluid of finite depth," J. Hydronaut., vol. 12, pp. 157-165, 1978 .

[40] D. W. Denbo, K. Lolain, J. S. Allen, A. Huyer, and R. L. Smith, "Current Meter Observations Over the Continental Shelf Off Oregon and California February 1981-January 1984," College of Oceanography, Oregon State Univ., Corvallis, OR, Data Rep. 112, Ref. 84-12, 1984.

[41] R. C. Beardsley, T. F. Duda, J. D. Irish, and S. R. Ramp, "The barotropic tide in the northeast south China sea," IEEE J. Oceanic Eng., vol. 29, pp. 1075-1086, Oct. 2004.

[42] F. S. Henyey and A. Hoering, "Energetics of bore-like internal waves," J. Geophys. Res., vol. 102, pp. 3323-3330, 1997

[43] H.-R. Kim, S. R. Ramp, and T. F. Duda, Internal Solitons in the Northeastern South China Sea Part II: Shoaling and Transformation in Shallow Water. unpublished.

[44] K. R. Helfrich, "Internal solitary wave breaking and run-up on a uniform slope," J. Fluid Mech., vol. 243, pp. 133-154, 1992.

[45] A. K. Liu, Y. Zhao, T. Y. Tang, and S. R. Ramp, "A case study of internal wave propagation during ASIAEX-2001,” IEEE J. Ocean. Eng., vol. 29, pp. 1144-1156, Oct. 2004.

[46] S. R. Ramp, C.-S. Chiu, F. L. Bahr, Y. Qi, P. H. Dahl, J. H. Miller, J. F. Lynch, R. Zhang, and J. Zhou, "The shelf-edge environment in the central East China Sea and its impact on low frequency acoustic propagation,” IEEE J. Ocean. Eng., vol. 29, pp. 1011-1031, Oct. 2004

[47] C. A. Blain, R. H. Preller, and A. P. Rivera, "Tidal prediction using the advanced circulation model (ADCIRC) and a relocatable PC-based system," Oceanogr. Mag., vol. 1, pp. 77-87, 2002.

[48] G. D. Egbert, A. F. Bennett, and M. G. G. Foreman, "TOPEX/POSEIDON tides estimated using a global inverse model," J. Geophys. Res., vol. 99, pp. 24 821-24 852, 1994.

[49] Y.-J. Yang, T.-Y. Tang, and S. R. Ramp, "Solitons northeast of Tung-Sha island during the ASIAEX pilot studies," IEEE J. Ocean. Eng., vol. 29, pp. 1182-1199, Oct. 2004.

[50] B. Ono, "Algebraic solitary waves in stratified fluids," J. Phys. Soc. Japan, vol. 39, pp. 1082-1091, 1975.

[51] J. R. Apel, R. F. Gasparovic, D. R. Thompson, and B. L. Gotwols, "Signatures of surface wave/internal wave interactions: Experiment and theory," Dynam. Atmos. Oceans, vol. 12, pp. 89-106, 1988

[52] M.-K. Hsu, A. K. Liu, and C. Liu, "A study of internal waves in the China Seas and Yellow Sea using SAR," Cont. Shelf Res., vol. 20, pp. $389-410,2000$

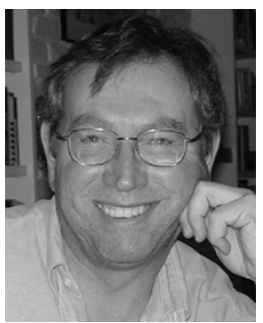

Steven R. Ramp received the M.S. degree in physical oceanography from the University of Washington, Seattle, in 1976, and the Ph.D. degree in physical oceanography from the University of Rhode Island, Narragansett, in 1986.

Since 1986, he has been with the U.S. Navy as a Professor at the Naval Postgraduate School, Monterey, CA, and a Program Officer at the Office of Naval Research, Arlington, VA. Prior to this, he spent time at the National Marine Fisheries Service, Woods Hole, MA. His research specialty is ocean observations from both ships and oceanographic moorings, and he has organized major expeditions to the Japan Sea, East China Sea, and South China Sea. He was the International Scientific Coordinator for the Asian Seas International Acoustics Experiment (ASIAEX). 


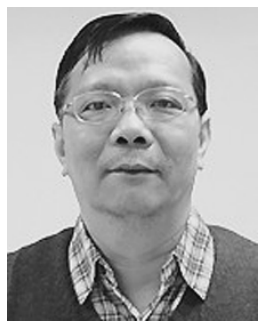

Tswen Yung Tang was born in Taiwan in 1952. He received the M.S. degree in physical oceanography from National Taiwan University, Taiwan, in 1975 and the Ph.D. degree in physical oceanography from North Carolina State University, Raleigh, in 1984.

In August 1993, he was appointed Professor of Physical Oceanography at the Institute of Oceanography, National Taiwan University. He was appointed Program Manager of the Division of Marine Science, National Science Council, Taiwan, in January 2004. His research interests include equatorial dynamics, variability of upstream of Kuroshio, Kuroshio intrusion at Luzon Strait, circulation in the South China Sea, and internal waves.

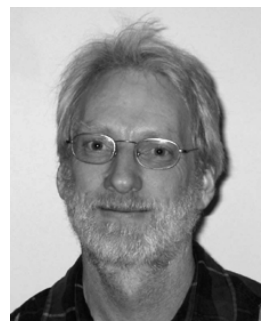

Timothy F. Duda received the B.A. degree in physics from Pomona College in 1979 and the Ph.D. degree in oceanography from the Scripps Institution of Oceanography, University of California, San Diego, in 1986.

He has been a Scientist with the Woods Hole Oceanographic Institution, Woods Hole, MA, since 1991. Prior to that, he held positions at the University of California, Santa Cruz. His three primary fields of study are ocean acoustic propagation, ocean internal gravity waves, and ocean mixing processes. $\mathrm{He}$ has modeled and analyzed fluctuations of ocean acoustic transmissions; has made electromagnetic-type internal-wave measurements; and performed in situ measurements of ocean microstructure.

Dr. Duda is a Member of the American Meteorological Society, the American Geophysical Union, and the Acoustical Society of America.

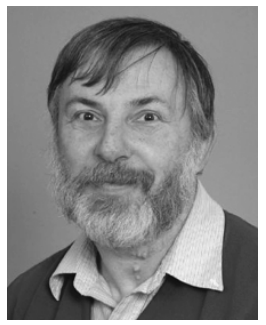

James F. Lynch (M'96-SM'03) was born in Jersey City, NJ, on June 3, 1950. He received the B.S. degree in physics from Stevens Institute of Technology, Hoboken, NJ, in 1972 and the Ph.D. degree in physics from the University of Texas, Austin, in 1978.

He was with the Applied Research Laboratories, University of Texas at Austin (ARL/UT) from 1978 to 1981 , after which he joined the scientific staff at the Woods Hole Oceanographic Institution (WHOI), Woods Hole, MA. He has been with WHOI since then and currently holds the position of Senior Scientist in the Applied Ocean Physics and Engineering Department. His research specialty areas are ocean acoustics and acoustical oceanography, but he also greatly enjoys occasional forays into physical oceanography, marine geology, and marine biology.

Dr. Lynch is a Fellow of the Acoustical Society of America and Editor-inChief of the IEEE JOURNAL OF OCEANIC ENGINEERING.

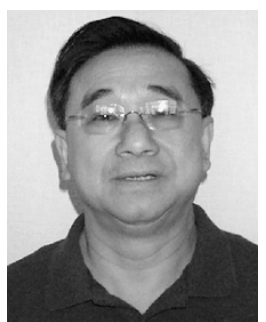

Antony K. Liu received the B.Sc. degree from National Chung-Hsing University, Taiwan in 1970, specializing in applied mathematics, and the Ph.D. degree in mechanics from the Johns Hopkins University, Baltimore, MD, in 1976.

Before he joined the NASA Goddard Space Flight Center, Greenbelt, MD, in 1986, he was with Dynamics Technology, Inc., Torrance, CA, as a Research Scientist, Group Manager, and later Section Head of Ocean Technology. He was promoted to Senior Scientist in 1992 at the Oceans and Ice Branch, Laboratory for Hydrospheric Processes, NASA/GSFC. Currently, he is in a three-year assignment detailed from NASA to the Office of Naval Research (ONR) Global-Asia, Tokyo, Japan. He has been a Principal Investigator (PI) of many research programs for the European Space Agency, the Japan Space Agency (JAXA), the Canadian Space Agency, and NASA. He also is a PI on ONR's Surface Wave Dynamics Experiment (SWADE) and Asian Seas International Acoustics Experiment (ASIAEX) and the National Oceanic and Atmospheric Administration's (NOAA's) CoastWatch projects. His research interests involve air-sea-ice interaction, satellite image processing, coastal monitoring, and nonlinear internal wave study.

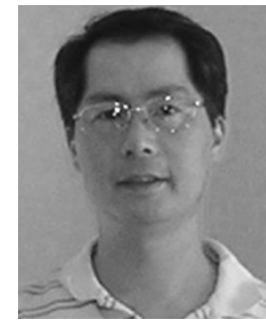

Ching-Sang Chiu received the B.S. degree in electrical engineering from Northeastern University, Boston, MA, in 1979 and the Sc.D. degree in oceanographic engineering from the Massachusetts Institute of Technology, Cambridge/Woods Hole Oceanographic Institution, Woods Hole, MA, joint program in 1985.

$\mathrm{He}$ is a Professor of oceanography at the Naval Postgraduate School, Monterey, CA. His research interests include ocean acoustics, acoustical oceanography, and coastal ocean processes and their influence on acoustic prediction. He has authored or coauthored more than 40 refereed publications in those subject areas.

Dr. Chiu is a Fellow of the Acoustical Society of America and Editor-in-Chief of the Journal of Computational Acoustics.

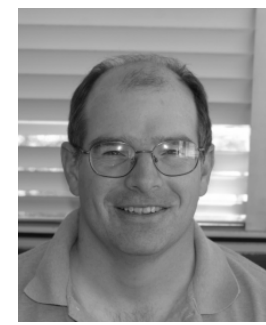

Frederick L. Bahr received the M.S. degree in physical oceanography from Oregon State University in 1991.

He was with Oregon State University for two years, where he worked for for Dr. Clayton Paulson. $\mathrm{He}$ then moved to Bermuda and was with the Bermuda Biological Station for Research for five years as part of the Bermuda Atlantic Time-Series (BATS) project and the Hydrostation S time series. $\mathrm{He}$ has been with the Oceanography Department, Naval Postgraduate School, Monterey, CA, for the

past six years.

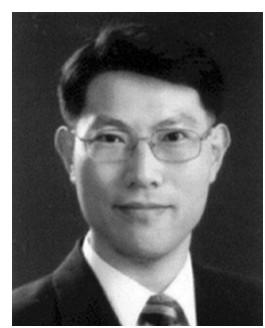

Hyoung-Rok Kim received the M.S. and Ph.D. degrees in oceanography from Seoul National University, Seoul, Korea in 1991 and 2001, respectively.

He was a Lecturer and Researcher in the Department of Oceanography and the Naval Institute of Maritime Affairs, Korean Naval Academy, Jinhae, Korea, from 1992 to 1996 . He was a National Research Council Postdoctoral Investigator with the Naval Postgraduate School, Monterey, CA, from 2002 to 2004 . He currently is a Research Associate in the School of Earth and Environmental Sciences, Seoul National University. His recent works have focused on the observation, data analysis, and numerical modeling of solitary internal waves in the ocean.

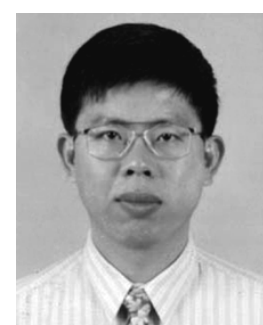

ical Union
Ying-Jang Yang was born in Taiwan, R.O.C., in 1967. He received the B.S. degree in oceanography and the Ph.D. degree in physical oceanography from the National Taiwan University, Taipei, Taiwan, in 1990 and 1996, respectively.

He currently is an Assistant Professor with the Department of Marine Science, Chinese Naval Academy, Kaohsiung, Taiwan. His research interests include internal tides and waves, current variation around Taiwan, and equatorial dynamics.

Dr. Yang is a Member of the American Geophys- 